UCRL 15097

P.0. 4163409

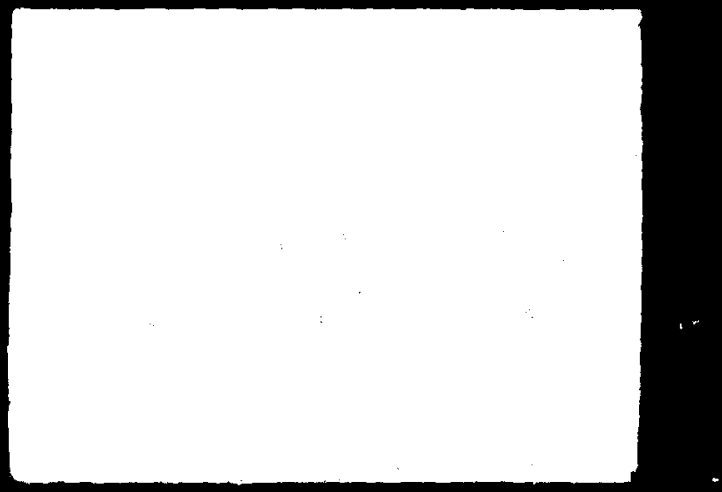




\section{MASTER}

MASTER

AND

MAGNET PROTECTION STUDY

FOR MFTF

LLL FINAL REVIEW

JUNE 1979

MAMTHM

IGC REPORT No, 679-7

SUBMITTED TO:

LAMPENCE LIVERMORE LABORATORY

Livermore, California

SUBMITTED BY:

INTERMAGNETICS GENERAL CORP,

GUILDERLAND, NEW YORK

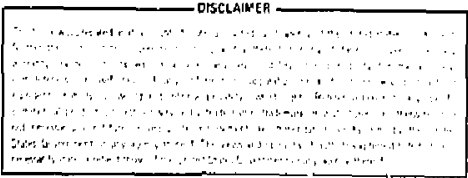




\section{MASTER \\ MASTER}

MASTER

MASTER 


\section{MASTER}

FOREWORD

This report covers work sponsored by the University of California, Lawrence Livermore Laboratory, under Purchase order 4163409. The Lawrence Livermore Laboratory Project Engineer is Daniel W. Shimer. The Program Manager of the study is Dr. Michael J. Hennessy.

Acknowledgement is also due to the many individuals at IGC whose skills have been essential in preparing this study, including Dr. R. T. Woods, A. W. Heintz, and R. F. DiGesare.

This report covers work performed for the period January 1, 1979, through June 29, 1979, and the report was submitted July 2, 1979. 


\section{ABSTRACT}

'ihis report summarizes the results of a Quench Detection and Magnet Protection Study for MFTF. The study was directed toward establishing requirements and guidelines for the electronic package ased to protect the MFTF superconducting magnets.

Two quench detection schemes were analyzed in detail, both of which require a programuable quench detector. Hardware and software recommendations for the quench detector were presented in the rejort as well as criteria for dumping the magnet energy in tle event of a quench.

Overall magnet protection requirements were outlined in a detailed Failure Mode Effects and Criticality Analysis, (FMECA). Hardware and software packages conpatible with the FMECA were recummended, with the hardware consisting of flexible, dedicated intelligent modules specifically designed for magnet protection. 
FOREWORD

ABSTRACT

LIST OF FIGURES

LIST OF TABLES

1.0 BACKGROUND HISTORY 1-1

2.0 DESIGN PHILOSOPHY 2-1

2.1 Reliability $2-2$

2.1.I System Design 2-2

2.1.2 Pretesting 2-2

$2.1,3$ Testing 2-3

2.1 .4 Interlocks 2-3

2.1,5 Diagnostios 2-3

2.2 Simplicity 2-4

2.2.1 Local Intelligent

Instrumentation and control 2-4

2.2.2 Interconnection 2-4

2.2.3 Modular Approach 2-5

2.2 .4 Inputs 2-5

$2.2,5$ Indicators and controls $2-5$

2.3 Stand-Alone Concept 2-6

2.4 Modularity 2-6

2.5 Noise and Isolation 2-6

2.6 Self-Test Features 2 2 8

2.7 Human Engineering 2-9

3.0 QUENCH DEPECTION 3-1

3.1 Quench Detector 3-1

3.1.1 Normal Zone propagation 3-1

3.1.2 Power Supply Noise 3-1

3.1.3 Mutual Inductance Effects 3-2

3.1.4 Inductance Changes in the Magnet 3-5

3.1.5 MFTF Quench Detector Requirements 3-6 
TABLE OF CONTENTS (Cont.)

$\underline{\text { Page }}$

3.2 Balanced Bridge Method 3-8

3.2.1 Discussion of the Principle 3-8

3.2.2 Algorithm Including Mutual
Inductance Effects

3.2.3 Description of Balanced
Bridge Module

3.2.4 Block Diagram 3-16

3.2.5 Software Flow Chart 3-17

3.2.6 Front Panel 3-18

3.3 Current Rate Method 3-19

3.3.1 Discussion of the Principle 3-19

3.3.2 Description of the Module 3-19

3.3.3 Black Diagram 3-21

3.3.4 Flow Chart 3-22

3.4 Quench Detector Connection 3-23

3.5 Quench Voting 3-23

4.0 MAGNET PROTECTION SYSTEM · 4-1

4.1 Overview 4-1

4.1.1 System Diagram and Instrumentation List $4-1$

4.1.2 Front Panel Layout and List of
Modules

4.1 .3 System Operation $\quad 4-10$

4.2 Criteria for Dumping and FMECA 4-13

4.3 Microprocessor Module 4-15

4.3.1 Description 4-15

4.3.2 Front Panel 4-16

4.3.3 Block Diagram $4-17$

4.3.4 Software 4-18

4.4 IGC Universal Input Indicator 4-19

4.4.1 Description 4-19

4.4.2 Front Panel 4-21

4.4.3 Block Diagram 4-22 
TABLE OF CONTENTS (Cont.)

Page

4.5 IGC Breaker Driver Interface Module

4.5.1 Description

4.5.2 Front Panel

$4-24$

4.5.3 Block Diagram

$4-25$

$4-26$

4.6 Quench Detector Voting Logic Modules

$4-27$

4.6.1 Description

4-27

4.6.2 Block Diagram

4-28

4.7 Quench Detector Input Relay

$4-29$

4.7.1 Description

$4-29$

4.8 IGC Current Controller Unit

$4-30$

4.8.1 Description

4.8.2 Front Panel

$4-30$

4.8 .3

$4-32$

4-33

4.9 Microprocessor Display

4-34

4.9.1 Description

4.9.2 Front Panel

$4-34$

$4-35$

5.0

CONCLUSION

5-1

6.0

REFERENCES

$6-1$ 


\section{LIST OF FIGURES}

Figure

Page

$3-1$

Electrical Representation and

$3-3$

Inductance Values

$3-2$

Balanced Bridge Model

$3-9$

$3-3$

Model for the Currerit Rate

$3-20$

3-4 Method

$4-1$

MFTF Quench Detector Connections

$3-24$

MPTF Electronics Subsystem

$4-2$

$4-2$

MFTF Magnet Protection Console

$4-8$

\section{LIST OF TABLES}

Table

Page

3-1

MFIF Quench Detector

3-7

Requirements Summary

$3-25$

$4-1$

Proposed Quench Voting Table

$4-3$

$4-2$

List of Non-protection Instruments

$4-5$

Iist of Protection Modules

Recommended for MFTF 
In the past, superconducting magnets have been inadequately protected. ${ }^{1}$ The natural inclination is to over-react and to dedicate a large computer system with comprehensive software to handle the entire task of magnet protection. An approach such as this is undesirable. Inadequate protecticn instrumentation can obviously lead to magnet devastation, and large computer systems can become expensive, complicated, and, more importantly, can be unreliable. A more sensible, reliable and effective solution to the problem of magnet protection utilizes intelligent microprocessor instrumentation, which provides inexpensive dispersed signal frocessing and simple lccal control. It has been this application of microprocessors that has enabled Intermagnetics General Corporation and nthers to streamline this difficult but important protection task.

In the complex MPTP system, magnet protection is of utmost importance and crucial to the value of the entire project. obviously, the time available for plasma experiments is directly related to magnet reliability and performance, which, in turn, requires an electronic-protection design that is conservative, highly effective, and easily maintained. Electronic components often fail. The ease of getting back on-line in the event of a component failure is related to the degree of modularity, the use of standard hardware, and diagnostic capability designed into the system. The present study is based on these ideas as well as IGC's experielce in magnet protection for commercial superconducting magnets ${ }^{2}$ applied to medicira and plasma physics, a recent example being TRW's Prototype Magnet system (PMS) where the end user of the magnet need not necessarily be an experienced superconducting magnst operator. 
The ultimate reliability of the MFTF magnet systern will be determined by the stability of the superconductor and magnet as a whole as well as the sensitivity and lifetime of the protection circuit components. Important design guidelines used in this study reflecting an emphasis on both reliability and simplicity are:

- Critical circuit paths should be simple with the number of comionents along each path minimized.

- Progranmable or selectzble features should be either hard-wires or contained in read-only-memory (ROM).

- Critical circuit paths should be periodically tested and monitored.

- Circuitry shoula be modularized for ease of maintenance and, wherever possible, interchangeable stand-alone modules should be used.

- The system should be interlocked, protecting the system from any possible operator error.

- All outside interfaces should be isolated and decoupled to prevent false triggering of the logic by noise.

- The protection system should be sufficiently independe't to survive an LLi computer failure, a power supply failure, and a facility mairpower-service failure.

- Redundancy should be included in the system so that a single component failure in the protection system will not alter the effectiveness of the piotection system and endanger the magnet.

- Self-testing during power up or after a magnet energy dump should be a requirement. 
- Diagnostics should be included in the system so that problems may be pinpointed by either real time readout or by recording what the status of the system was at any time before or during system failure.

The importance of establishing a solid design is underlined by the fact that; if a quench occurs and goes undetected or the protection circuits fail, the magnet could be damaged. Also, jf the fast dump circuitry trips falsely, the magnet would be needlessly de-energized, dissipating helium and resulting in down time.

In the next sections, specific detailed guidelines are given for the design of tho MFTF protection system, emphasizing the criticality of the protection task.

\section{$2.1 \quad$ Reliability}

Selow are listed the specific guidelines associated with design reliability - an important reguirement in the overall design philosophy recomended for METF. It should be noted that all reliability requirements can be met with commercial, off-theshelf hardware.

\subsubsection{System Design}

The general guidelines for the system design should include minimization of the number of components along critical paths, especially along paths between the quench detectors and $6000 \mathrm{Amp}$ circuit breakers. Reliance on only a single component, especially a microprocessor, for a critical function should be avoided. Redundant circuitry and busses should be included where necessary to avoid having the entire system dependent on a single element.

\section{$2.1 .2 \quad$ Pretesting}

To overcome infant mortality failure, ali parts installed in the system should be burned in for at least 100 hours. This will 
insure that most failures due to defective components, especially IC's and transistors, will be identified before helium is committed. A useful device to be used for this pretesting of the entire system is a magnet simulator, a piece of test equipment designad to simulate magnet sensors and voltages as they would appear in the cooled magnet.

\subsubsection{Testing}

While the magnet system is being energized or after a quench, the protection system should be designed to activate self tests for insuring the integrity of the hardware. For example, the quench detectors should be put in a test mode to verify that the input amplifiers are working. (Other tests are enumerated in the foregoing sections.) These tests will be valuable in maintaining the syster integrity over a long period of time and will pay for themselves by increasing the mean time between operational failures. If tests do not pass, the normal response should be to lock up the current controller so that the magnet. cannot be charged or, if charged, that it is automatically discharged to zero current. Details of how this philosophy is incorporated in the design will be discussed in subsequent sections.

\subsubsection{Interlocks}

The basic guidelines for interlocks should be that interlocks be provided so that (1) the operator cannot damage the magnet through any manipulation such as inadvertent testing, or (2) the system cannot be operated unless the system has been fully connected and tested.

\subsubsection{Diagnostics}

If the magnet system fails, it is extremely important from a reliability standpoint to know exactly what the conditions were 
prior to and at the time of failure. The puxpose of the diagnostics is to reconstruct events leading up to the magnet energy dunp since there is inevitably a question as to whether a dump was caused by a real quench or by extraneous circumstances. Adequate memory, therefore, should be providad to read out the conditions of tile system at any time before a critical transition has occurred. This event recording capability or "snapshot" capability should be built into the entire system. Examples of information that should be recorded are relay and valve positions, bus conditions, and magnet current and tap voltages before quench.

\section{$2.2 \quad$ Simplicity}

One of the most important factors that affects system reliability, cost and performance is simplicity. To achieve maximum simplicity, the following guidelines are recommended.

\subsubsection{Local Intelligent Instrumentation ind Control}

When computer intelligence is reguired, the intelligence should be segmented as much as possible into single, straightforward tasks that can be handled by a dedicated microprocessor. This keeps the software simple, makes the entire system easier to debug and maintain. For example, in the MFTF, a large task like quench detection can be partitioned into relatively simple tasks among several dedicated microprocessors. Microprocessors have the advantage of being simple, interchangeable and independent to the degree that, if one fails, others can continue looking for normal zone formation without interference. Each intelligent instrument should also have provisions for self-test on command, which will reduce the complexity of a complete system test to that of assessing the condition of each independent moduie.

\subsubsection{Interconnection}

Between modules, the system should include a non-critical communication bus for diagnostics testing and transmission of 
non-vital information, and a separate bus for criticai tasks such as dumping. Ench critical bus should be accompanied by a redundant bus for extra reliability. Each critical bus should be kept completely independent of all the other busses and flow through separate IC's with no interconnection between them. This redundancy should be carried as far as possible even to the inclusion of redundant breakers. This independence insures complete redundancy and thus enhances overall system reliability. The busses should be standardized for all units so that the modules can be interchanged and, if necessary, expanded.

\subsubsection{Modular Approach}

Modules siould be used as much as possible to simplify and reduce cost.

\subsubsection{Inputs}

Inputs to the protection system should be either single contacts, as in the case of relay or valve positions, or transistor drivers capable of driving LED's. Each instrument, such as the helium level indicator, should have a single bit output indicating above or below a settable low limit threshold. Continuous reading of variables like the helium level could be provided for data logging but is not requıred for quench protection hardware. Only a single threshold output from each instrunent is required for protection. The thresholds normally do not change.

\subsubsection{Indicators and Controls}

The front console should include clearly-marked visual indications of the status of each input. The controls and indicators should be simple, and compatible with human engineering needs. 
A key part of the design philosophy recommended in this study is the stand-alone concept. The system should be designed so that individual modules or parts of the system may fail without quenching the magnet or without leaving it unprotected. For example, if the central MFTF computer goes down, or if the main facility power service fails, the protection systerı should have enough local inteiligence and control to ramp the magnet down slowiy while, at the same time, protecting it in the unlikely but possible event of a quench. The system should also be designed so that if a problem exists which does not endanger the magnet, the operator can take command at the console and override automatic control. The stand-alone concept is consistent with the simplicity, modularity and human engineering aspects of the design.

\section{$2.4 \quad$ Modularity}

Inherent in the design should be modularity to the extent that modules may be isolated, removed and replaced with a minimum of magnet down time. Modularity also simplifies overall system complexity and reduces system costs. Using common bus structures, the system should be flexible enough to expand, if necessary. In this study, we recommend $12-1 / 4^{\prime \prime} \times 5-3 / 4 "$ modiles ( $1 / 3$ of a 19 " rack) because this size allows adequile cooling and adequate space to include three or more large wirewrap circuit boards, power supplies and front pane.. area without crowding.

\section{$2.5 \quad$ Noise and Isolation}

The environment of the MFTF system is expected to be quite noisy. Precautions should be made to reduce RFI and EMI from all power sources and fror. the incoming $60 \mathrm{~Hz}$ power lines. The following 
guidelines should be followed to improve noise imrunity.

1) All instrumentation should be enclosed in metal enclosures with all external cables and connectors shielded.

2) A single ground should be defined for the system. (This ground should be: tied to the center tap of both dump resistors to reduce voltage breakdown.)

3) Digital IC's should have high noise immunity at least as good as B-type CMOS.

4) Line Eilters to reject EMI and RFI should be included in each module of instrumentation.

5) A11 external inputs to the system should be optically coupled and clocked so that transients cannot couple into the logic. optical couplers should be specified in excess of $20 \mathrm{Volts} / \mathrm{nsec}$ for common mode transient immunity (see IGC input module in section 4.4 ).

6) Voltage taps should be isolated from quench detector circuits during a fast dump to prevent any damage to the taps in the magnet. If magnet taps wers to be destroyed in the cryostat, it would be almost impossible to sense a quench.

7) Isolation amplifiers should be used in quench detectors to reduce noise coupling into the system.

8) Extreme care should be taken in isolating the breaker driver circuits so that switching transients do not couple into the protection logic.

9) Contacts should be used wherever possible to simplify the design and reduce noise. For example, thermostat contacts should be used for over-temperature indications as opposed to active thermometers that are sensitive to noise. 
(10) Comparators should be designed with filtering and hysteresis.

The noise sensitivity of the system will influence the ultimate reliability of the protection system, especially in the case of the quench detectors which can be prone to tripping due to noise transients if improperly designed.

\section{$2.6 \quad$ Sej i-Test Features}

The protection system should include provisions for self-testing and diagnostics. This will both greatly enhance overall protection system reliability as well as streamline protection system maintenance. Self-test features should include:

1) Watchiog timers for all microprocessors. In most cases, these circuits should lock out the microprocessor from interacting with the rest of the system and alert the operator. If the operator does not respond in a reasonable amount of time, the system should respond by ramping the magnet down slowly.

2) All cables should be interlocked so that the magnet cannot be charged if a cable is disconnected.

3) Backup power sources should be constantly monitored.

4) Compressed air lines that power critical relays should be constantly checked.

mest requirements for the quench detectors should include:
1) Continuity tests for the voltage taps.
2) Isolation amplifier tests,
3) Algorithm tests. 
4) Output bus driver tests.

5) Timeout $\operatorname{logis}$ if the microprocessor fails.

6) Cross comparisons between redundant busses such as the fast dump bus.

Redundancy should be added in cases where critical sensors and circuits cannot be checked. A magnet simulator (explained in section 2.1.2) should also be connected periodically to check parts of the system that cannot be checked otherwise.

\section{$2.7 \quad$ Human Engineering}

In viek of the complexity of the MFTF, simplicity of operation is of primary importance. One concept held by Ifr. is that the operator should not need a manual to understand what state the system is in, what problems (if any) exist, or how the system is responding to those problems. Funutions that require special trained operator intervention should be guarded by using keylock switches. In addition, wall-mounted panic buttons and "ramp to zero current" or "slow discharge" buttons should be available for emergencies. For indicating the status of the system, LED indicators and adequate srapshot memory to record the state of the system at dump for later readout are recommended.

From a human engineering standpoint, the current controller is the most important hardware component. This is where the operator interacts with the magnet directly. The front panel should be designed so that the operator can use the controller without : manual. The front panel should have enough information to tell the operator what the magnet current levels and rates are programmed to. Meters should indicate how the magnet is performing. 
The operator should be able to override computer control and take control of the magnets individually or as a group. The current controller is described in section 4.8 . 


\subsection{Quench Detector}

\subsubsection{Normal Zone Propagatjon}

Quench behavior is difficult to predict. Normal zone propagation in the MFTF magnet may take many forms depending upon the nature of the event that triggers the normal zone formation. The results of the MFTF test coils show that normal zones can propagate at a velcsity of one meter per second. ${ }^{3}$ Analysis shows that some zones can form very rapidly and thermally run away in one second. Other zones may form more gradually.

LLL estimates that if normal zones form that exceed $\frac{1}{2}$ to 2 turns long, the magnet conductor would be endangered. "To protect the magnet from overheating, it is recommended that the magnet be discharged at a rate that woula put 1000 volts auross its terminals. About 10 seconds is available from time of detection to time of initiating the dump. 6

other harmless normal formations can also occur that pose no immediate damage to the magnet. Stable normal zones may form less than one-half a turn long lasting forever until the magnet current is reduced, at which time they may vanish. Protection in the event that a stable normal zone appears should take the form of a slow discharge of the magnet as opposed to a fast dump. Finaliy, other events may occur in which a normal zone appears instantly, then gradually recovers. The latter requires no action from the quench protection system.

All of these requirements must be met by the protection hardware and software. The quench detectors described in Sections 3.2 and 3.3 can distinguish between a nonotonically increasing normal zone beyond $b_{2}$ turn phich is defined as a quencly and other non-quench conditions such as a recovering normal zone or steady state zone. A sumnary of requirements for the quench detector is found in Section 3.1.5.

\subsubsection{Power Supply Noise}

The power supply noise will be characterized by voltage ripple 
across the magnet in the form of a complex SCR wave form with a $360 \mathrm{~Hz}$ fundamental frequency with an amplitude of 12 volts RMS. At constant current the average voltage will be approximately zero. When the magnet current is being changed the average voltage will increase proportional to dI/at due to the inductance of the magnet.

The effect of the power supply noise on the quench detectors appears as common-mode noise across the magnet taps whicn has to be balanced and filtered out at the quench detector. The $\mathrm{AC}$ noise ccross the taps also couples to the cryostat ground and forms loop currents. AC loop currents causes AC unbalances in the ruench detector which are very difficult to filter out. Shielcod coaxial cables on taps help reduce the AC loop currents somewhat by letting the shields carry the current, but some filtering is still required. Inductive coupling into the taps is also a problem and should be eliminated by twisting the taf.3 together wherever possible.

\subsubsection{Mutual Inductance Effects}

Figure 3-1 shows a representation of the magnet circuit for mutual inductance between the MFTF magnets, The voltage across a given segment of the magnet is proportional to the rate of change of current in the parent magnet as well as being proportional to the rate of change of the current in the neighboring magne:" The formula for the voltage of segment a is expressed in terms of the mutual inductance.

$$
\begin{aligned}
v_{a}= & \left(I_{a}+M_{a b}+M_{a c}+\ldots M_{a h}\right) \dot{I}_{1}+ \\
& \left(M_{a 2}\right) \dot{I}_{2}+I_{1} R \text { (assuming a normal zone) }
\end{aligned}
$$

The first term proportional to $\dot{I}_{1}$ can be lumped together as an effective inductance ( $I_{a}$ eff) which does not change. If $\dot{I}_{2}$ were zero, the system behaves as a single magnet and a conventional 


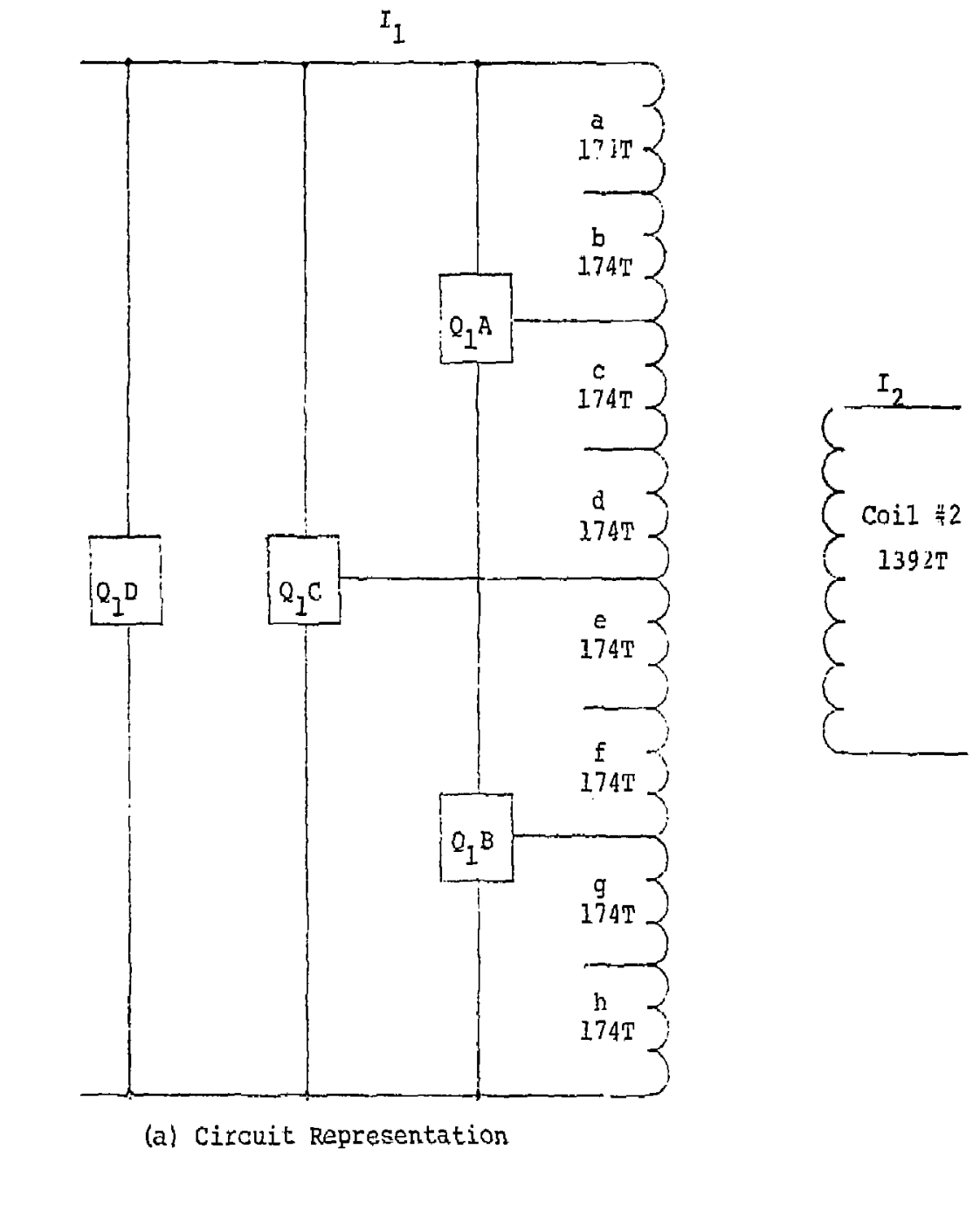

(a) Circuit Representation

\section{Segment}

Mutual Inductance Between Magnet 2 and Segment of Magnet 1 
passive resistor brioge could be used to buck out the inductive voltage across the tap. A quench in the segment would appear as a voltage unbalance in the bridge proportional to the size of the normal region. Because of the coupling $\mathrm{M}_{\mathrm{a} 2}$ Irom Magnet 2. quench detection terhniques that use only parameter associated with magnet 1 are not adequate. Compensation due to $\dot{I}_{2}$ effects must be made in order to unscramble the quench signal. The magnitude of the $\dot{I}_{2}$ effect is worst during ramping and can be estimated from the mutul 1 inductance calculations made at LLL shown in Figure $3-1$.

The voltage offset induced by magnet 2 into quench detector QlA central tap (using Figure $3-1$ ) is

$$
\begin{aligned}
& \left.\Delta V_{1 A}=M_{a 2}+M_{b 2}-M_{c 2}-M_{d 2}\right) \dot{I}_{2} \\
& \Delta V_{1 A}=17.4 \mathrm{IV}
\end{aligned}
$$

asfurning magnet 2 is being charged at 12 volts which corresponds to current rate of $1 \mathrm{amp} / \mathrm{sec}$.

For quench detector $Q_{1 c^{\prime}}$ the induced voltage offset is

$$
\begin{aligned}
& \Delta V_{1 \mathrm{c}}=\left(M_{\mathrm{a} 2}+M_{\mathrm{b} 2}+M_{\mathrm{c} 2}+M_{\mathrm{d} 2}-M_{\mathrm{e} 2}-M_{\mathrm{f} 2}-M_{\mathrm{g} 2}-M_{\mathrm{h} 2}\right) \dot{I}_{2} \\
& \Delta \mathrm{V}_{1 \mathrm{c}}=70.2 \mathrm{mv}
\end{aligned}
$$


By comparison, $Q_{1 B}$ has an induced voltage comparable to $Q_{1 A}$.

$$
\begin{aligned}
& \Delta V_{13}=\left(M_{e 2}+M_{f 2}-M_{g 2}-M_{h 2}\right) \dot{I}_{2} \\
& \Delta V_{1 B}=16.0 \mathrm{mV}
\end{aligned}
$$

For quench detectors such as $Q_{1 D}$ that examine the voltage across the entire coil, the effect is more dramatic. Here the induced vol'age is

$$
\Delta V=\left(N_{a 2}+M_{b 2}+\ldots+M_{h 2}\right) \dot{I}_{2}=1.24 \text { volts }
$$

The quenched conductor will develop a voltage drop 27 mv/meter according to Section 2.2. In order to resolve one moter, as recommended, the queuch detectors must subtract out or compensate for the induced voltage. A credible algorithm will require knowledge of the mutual inductances which should be measured in initial tests.

\subsubsection{Inductance Changes in the Magnet}

In a large structure like $\mathrm{MFTF}$, the magnet windings are expected to expand and contract during charging and discharging. This will cause inductance changes as the magnet is rampex. Inductance changes could be misinterpreted as a section of the conductor going normal. One method of monitoring incuctance changes would be to sense deviation of linearity of the magnetic field as a func. tion of current. A pickup coil around the magnet would also be able to detect a change in inductance. Although pickup coils or field sensors are not forseen as being requires for quench protection since the voltage thresholds are very high, such sensors would be recommended as diagnostic tonis. 
Inductance changes may occur rapidly due to conductor slippage causing large voltage spikes in the magnet. Quench detectors should be capable of filtering out large voltage spikes. Inductance changes will probably be less than 18 based upon allowable thermal and magnetic stresses. This corresponds to approximately $120 \mathrm{mv}$ shift ( 1 o of $12 \mathrm{~V}$ ramp rate) which corresponds to less than $\frac{1}{2}$ turn being normal. Precautions should be taken in the quench detector to compensate for these changes if they happen to become larger than expected.

\subsubsection{MFTF Quench Detector Requirements}

In Table 3-1 is a summary of parameters associated with MFTF quench protection. Any quench detector must be compatible with these parameters. Because of the difficulty in predicting the exact behavior of such a large magnet as MFTF, the quench detector should be as flexible as possible, Parameters, such as voltage thresholds and quench detector response time; should be programmable.

Two methods of quench detection are recommended. The first method, the balanced bridge approach, has been used successfully in the past with large magnet systems and is being used currenty with IGC magnets. ${ }^{2}$ The current rate method has been used at ORNL and has been found to be quite effective. ${ }^{8}$ MFTF requires some modification of these basic techniques because of the coupling between the two large magnets. 
TABLE 3-1

METF Quench Detector Requirements Summary

\begin{tabular}{|c|c|}
\hline Magnet Ënergy & $220 \mathrm{MJ}$ \\
\hline Max Voltage Across Magnet & $1000 \mathrm{~V}$ \\
\hline Max Magnet to Cryostat Voltage & $500 \mathrm{~V}$ \\
\hline Magnet Inductance & 12 Henries \\
\hline $\begin{array}{l}\text { Mutual Inductance Betireen } \\
\text { Mägnets }\end{array}$ & 1 Henry \\
\hline Maximum Charging voltage & \pm 12 volts \\
\hline Magnet Voltage (RMS) & $\simeq 12$ volts \\
\hline $\begin{array}{l}\text { Induced Voltage from other } \\
\text { Magnet }\end{array}$ & $\simeq 1.5$ volts RMS \\
\hline Breaker Activation Time & $<100 \mathrm{~ms}$ \\
\hline Quench Normal Zone Length & $\approx$ one $\operatorname{turn}=15.75$ meters \\
\hline Quench Normal Resistance & 15.75 meters $\times 46 \mathrm{n} \Omega / \mathrm{cm}=72 \mu \Omega$ \\
\hline Quench voltage (l meter) & 0.435 volts $@ 6000$ amps \\
\hline Quench Velocity & $\begin{array}{l}\approx 1 \text { meter } / \mathrm{sec} \text { or } 27.6 \mathrm{mv} / \mathrm{sec} \\
\text { a } 6000 \text { amps }\end{array}$ \\
\hline Resolution Recommended & $27 \mathrm{mv} \& 6000$ amps \\
\hline Max Tolerable Noise & $=3 \mathrm{mv}$ for $\mathrm{s} / \mathrm{N}=10$ \\
\hline Recommended Bandwidth & $10 \mathrm{~Hz}$ \\
\hline $\begin{array}{l}\text { Recommended Stability of } \\
\text { Quench Detector (no mutual) }\end{array}$ & $<27.6 \mathrm{mv} / 12 \mathrm{v}=0.23 \mathrm{~g}$ \\
\hline $\begin{array}{l}\text { Degree of Balance Required } \\
\text { to Cancel Mutual }\end{array}$ & $<27.6 \mathrm{mv} / 1.5 \mathrm{v}=1.88$ \\
\hline $\begin{array}{l}\text { Available Time from Onset } \\
\text { of Quench to Dump }\end{array}$ & Programmable (1 - 15 seconds) \\
\hline $\begin{array}{l}\text { Quench Detection Time } \\
\text { from Onset }\end{array}$ & $\begin{array}{l}\text { Programmable in increments of } \\
100 \mathrm{~ms}\end{array}$ \\
\hline
\end{tabular}




\subsection{Balanced Bridge Method}

\subsubsection{Discussion of the Principle}

A model of the balanced bridge method used for quench detection is shown in Figure 3-2. The method involves comparing the voltage across taps in the magnet to voltage arops across resistors which are arranged in a bridge circuit. In the diagram $\Delta V$ is the unbalance signal processed by the quench detector. When the bridge is initially balanced $R_{1}$ and $R_{2}$ are adjusted so that $\Delta \mathrm{V}$ is nulled. Note at balance, if $\mathrm{v}_{\mathrm{a}}$ and $\mathrm{v}_{\mathrm{b}}$ are zero, the null point is independent of the charging voltage $v_{1}$.

The balanced bridge works as follows. If the rate of change of $I_{2}$ is assumed to be gero, $V_{a}$ and $V_{b}$ represent the resistive voltage drops in the respective segments $\mathrm{L}_{a}$ and $\mathrm{I}_{b}$. (For a superconductor, $v_{a}$ and $v_{b}$ should be zero.) If a normal zone propagates equally in segments $L_{a}$ and $L_{b}$, then $V_{a}=V_{b}$ and the normal zone would not be detected. If, on the other hand, the normal zone only appeared in segment $L_{b}$, the unbalance signal $\Delta V$ would be one half of the voltage drop across the normal zone, i.e. $\Delta V=\frac{1}{2} V_{b}$. 


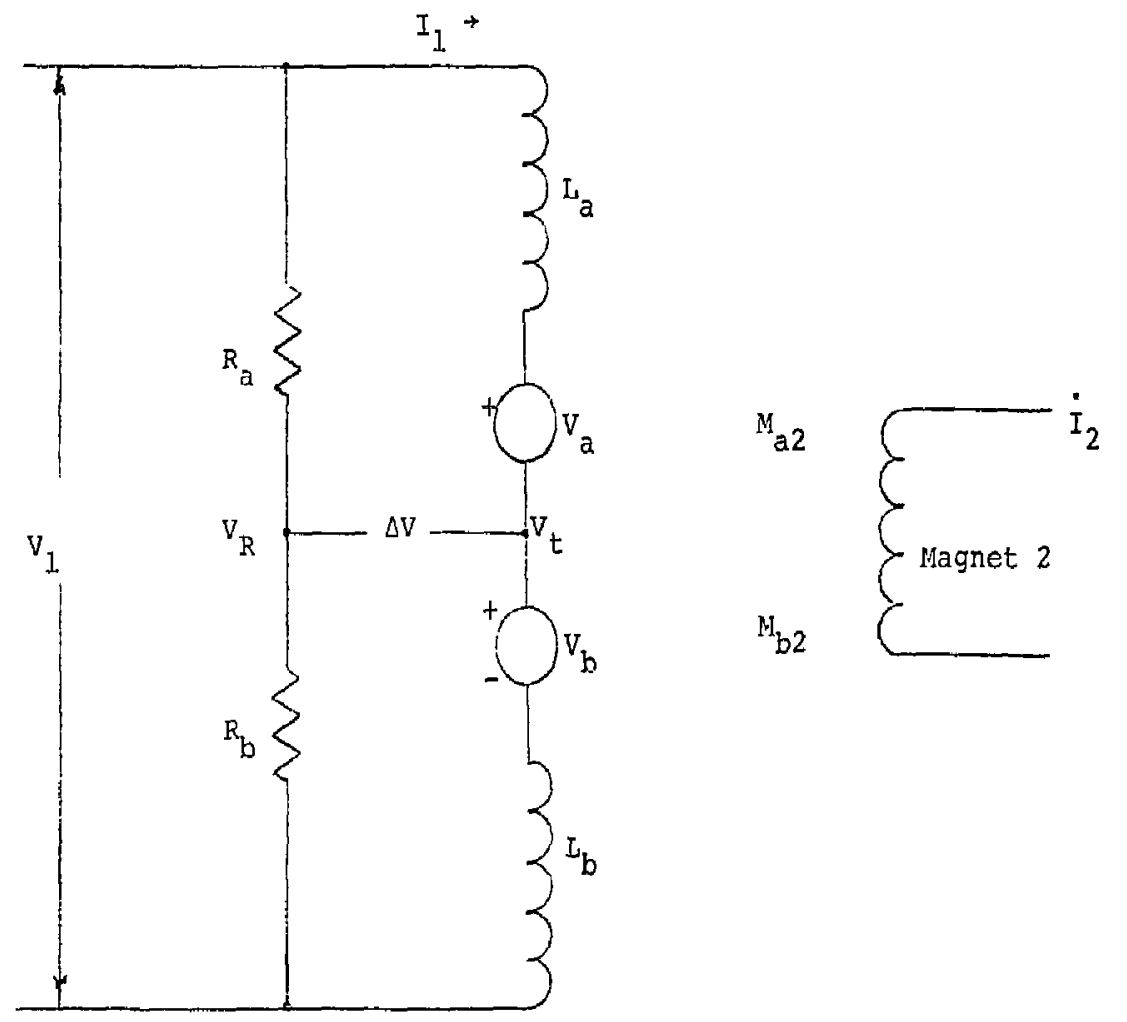

NOTE: $\quad V_{R}=\frac{R_{b}}{R_{a}+R_{b}} V$

Using Laplace Transforms

$$
\begin{aligned}
& V=V_{a}-V_{b}=S I_{1}\left(I_{a}+I_{b}\right) \\
& V_{T}=S I_{2} I_{1}+V_{b} \\
& V_{T}=\frac{S L_{2}}{S L_{1}+S L_{2}}\left(V-V_{a}-V_{b}\right)+V_{b} \\
& \Delta V=V_{T}-V_{R}=\frac{I_{2}}{I_{1}+I_{2}}\left(-V_{a}-V_{b}\right)+V_{b}
\end{aligned}
$$

For equal a ms

$$
\Delta V=\frac{1}{2}\left(V_{b}-V_{a}\right)
$$

FIGURE 3-2. BALANCED BRIDGE MODEL 
For the real case when magnet 2 has current changing, the voltage seen at $v_{a}$ due to mutual inductance will be

$$
\begin{aligned}
& V_{a \text { (induced) }}=M_{a 2} \dot{I}_{2} \\
& \text { and } V_{b \text { (induced })}=M_{b 2} \dot{I}_{2} \\
& \text { so that the total effect is } \\
& \Delta V_{(\text {induced })}=\left(M_{b 2}-M_{a 2}\right) \dot{I}_{2}
\end{aligned}
$$

The inductive signal must be anticipated by the guench detector and subtracted out from the unbalanced signal in order to accurately detect a quench forming. 


\subsubsection{Algorithrn Including Mutual Inductance Effects}

Once a technique for generating a signal proportional to the length of the normal zone has been established, such as the balanced bridge method, some signal processing is required to test whether or not the quench has progressed far enough to warrant a fast dump. In this section, some ground rules are established in terms of the parameters required and the type of calculations that need to be performed.

Below is a list of parameters that are required for an algorithm for quench detection in magnet 1 of $\mathrm{MFTF}$.

\begin{tabular}{|c|c|}
\hline V1 & $\begin{array}{l}\text { Low threshold above which indicates } \\
\text { the onset of normal zone formation. }\end{array}$ \\
\hline V2 & $\begin{array}{l}\text { Middle threshold above which indi- } \\
\text { cates dangerously high normal zone } \\
\text { formation. }\end{array}$ \\
\hline v3 & $\begin{array}{l}\text { High threshold above which indicates } \\
\text { a critical normal zone which warrants } \\
\text { an immediate dump. }\end{array}$ \\
\hline$t_{1}$ & $\begin{array}{l}\text { Maximum time available from the onset } \\
\text { of a normal zone above the second } \\
\text { threshold to complete breaker acti- } \\
\text { vation. }\end{array}$ \\
\hline$t_{2}$ & $\begin{array}{l}\text { The maximum time a steady state } \\
\text { normal zone is allowed to exist } \\
\text { without ramping down. }\end{array}$ \\
\hline$t_{B}$ & $\begin{array}{l}\text { opening time of the breaker from } \\
\text { energization to current interruption. }\end{array}$ \\
\hline$t_{d}$ & $\begin{array}{l}\text { Time available from the onset of a } \\
\text { normal zone to quench recognition. }\end{array}$ \\
\hline$t_{s}$ & Sample time between points. \\
\hline $\mathrm{N}_{\mathrm{s}}$ & Number of samples. \\
\hline$t_{p}$ & $\begin{array}{l}\text { Processing time allotted to recognize } \\
\text { a quench. }\end{array}$ \\
\hline$V_{B}$ & Continuously averaged baseline. \\
\hline
\end{tabular}




\begin{tabular}{|c|c|}
\hline$v_{B L}$ & $\begin{array}{l}\text { Maximum baseline drift tolerated } \\
\text { without warning the operator. }\end{array}$ \\
\hline$\Delta V$ & $\begin{array}{l}\text { Unbalanced signal averaged over } \mathrm{N}_{\mathrm{S}} \\
\text { samples minus the baseline. }\end{array}$ \\
\hline$\Delta \vec{V}$ & $\begin{array}{l}\text { First derivative of } \Delta V \text { averaged over } \\
\mathrm{N}_{\mathrm{s}} \text { samples. }\end{array}$ \\
\hline$\Delta V$ & $\begin{array}{l}\text { Second derivative of } \Delta V \text { averaged over } \\
\mathrm{N}_{\mathrm{S}} \text { samples. }\end{array}$ \\
\hline $\mathrm{M}_{12}$ & $\begin{array}{l}\text { Mutual inductance of segment monitored } \\
\text { due to other magnet (magnet } 2 \text { ). }\end{array}$ \\
\hline $\mathrm{L}_{1}$ & $\begin{array}{l}\text { Self inductance of section monitored } \\
\text { (for } Q . D \text {. ID that would be the entire } \\
\text { magnet } 1 \text { ). }\end{array}$ \\
\hline$\dot{I}_{1}$ & Rate of current change in magnet 1 . \\
\hline $\mathrm{I}_{2}$ & Rate of current change in magnet 2 . \\
\hline $\mathrm{M}_{12}^{\mathrm{U}}$ & $\begin{array}{l}\text { Mutual inductance between magnet } 2 \\
\text { and the upper part of the section } \\
\text { monitored in a balanced bridge } \\
\text { arrangement. }\end{array}$ \\
\hline $\mathrm{M}_{12}^{\mathrm{L}}$ & $\begin{array}{l}\text { Mutual inductance between magnet } 2 \text { and } \\
\text { the lower part of the section monitored } \\
\text { in a balanced bridge arrangement. }\end{array}$ \\
\hline$\Delta M_{12}=M_{12}^{U}-M_{12}^{L}$ & $\begin{array}{l}\text { Differential mutual inductance between } \\
\text { the upper section and the lower section } \\
\text { and magnet } 2 \text {. }\end{array}$ \\
\hline
\end{tabular}

The quench detector should continuously calculate the baseline $V_{B^{\prime}}$ the resistive voltage signal $\Delta V$, the voltage derivatives $\Delta \dot{v}$ and $\Delta i \dot{v}$. The total processing time is dependent on the complete detection algorithm and the analog-to-digital converter rates.

In a balanced bridge quench detector such as Q. D. $1 A$ in Figure $3-1$, the induced voltage from magnet 2 is continuously subtracted from the row input signal so that

$$
\Delta V=V_{\text {bridge }}-\Delta \mathrm{M}_{12} \dot{\mathrm{I}}_{2}-\mathrm{V}_{\text {Baseline. }}
$$


For a current rate quench detector, which will be discussed in section 3.3, such as Q. D. ID in Figure 3-3, the induced voltage from magnet 1 and magnet 2 is subtracted from the total voltage across the magnet so that

$$
\Delta \mathrm{V}=\mathrm{v}_{\text {magnet }}-\mathrm{M}_{12} \dot{\mathrm{I}}_{2}-\mathrm{L}_{1} \dot{I}_{1}-\mathrm{V}_{\text {baseline }}
$$

Once the quench detector processes the resistive signal $\Delta V$, a series of decisions must be made as to whether protective action should be initiated.

Below is an example of the type of algorithm a quench detector must execute in order to protect the magnet.

\section{Conditions}

$$
\Delta V>V_{3}
$$

$\Delta \mathrm{V}>\mathrm{V}_{2}$ for $\mathrm{N}_{\mathrm{s}} \mathrm{t}_{\mathrm{s}}$ time and $\Delta V$ monotonically increasing

$v_{1}<\Delta v<v_{3}$ for a time $t_{2}$

\section{Response}

Initiates a dump at 1000 volt rate

Initiates a dump at 1000 volt rate

Instructs magnet protection microprocessor to decrease currents until normal zone disappears 


\subsubsection{Description of Balanced Bridge Module}

In order to meet the requirements listed in sections 3.2 .3 and 3.1.5, a programmable quench detector should be used. Such a unit is commercially available from IGC. A block diagram of the unit is shown in section 3.2.4.

The heart of the quench detector is a small microprocessor which is used for signal averaging, buffering, computation, and communication. The users algorithm is contained in $4 \mathrm{~K}$ bytes of read-only menory (ROM) with $4 \mathrm{~K}$ bytes of random-access-memory (RAM) for scratch pad memory and data storage.

Below is a summary of components and features contained in the module:

- Input Section - Al1 balancing networks, signal amplifiers, and test circuits appear in this section. The test circuits check voltage tap continuity and exercises the input isolation amplifier and $A D C$ under program control.

- Slow ADC - This is the primary ADC used for digitizing the quench signal.

- Fast $A D C$ - This board contains a secondary $\overline{A D C}$ used to cross check the sIow $A D C$ and also monitors ambient temperature for compensation.

- Interface - This board contains all microprocessor interfaces and logic for the quench detector.

- Microprocessor - Controls all testing, computations and communication.

- Fast Dump Bus - This output bus contains two lines (one for redundancy) capable of activating the $6000 \mathrm{~A}$ fast dump breakers. The bus is opticaliy coupled for noise isolation and is fail proof. 
- Conmunication Bus - This is an I/O bus for communication between quench detectors and the main microprocessor. It also contains inhibit sighals which lock up the quench detector in case of a fault. The communication bus is normally a 20 ma TTY compatible serial bus. For MFTF an IEEE-488 bus may be more appropriate.

- $\dot{I}_{1}, \dot{I}_{2}$ Bus - This input bus is used for transmitting the rate of change of current to other quench detectors for processing. This is necessary in a two-magnet environment. The current rate bus is separate from the communication bus for extra reliability and speed.

- Watchdog Timer - This circuit latches up the quench detector if the microprocessor fails to respond every second.

- Front Panel controls - The quench detector is capable of displaying all the parameters j.nvolved with quench detection. Thresholds and times will be fixed and contained in read-only-memory and cannot be set from front panel except during initial installation tests. During normal operation, the quench detector runs unattended. In the event of a quench, data is recorded in each quench detector to examine the status of the magnet at quench.

- Noise Isolation - The module is especially designed for noisy environments. The input amplifier is an isolation amplifier with a common mode rejection ratio greater than $120 \mathrm{db}$. In addition, there is $60 \mathrm{~Hz}$ and $360 \mathrm{~Hz}$ prefiltering before the signal is averaged and processed. 


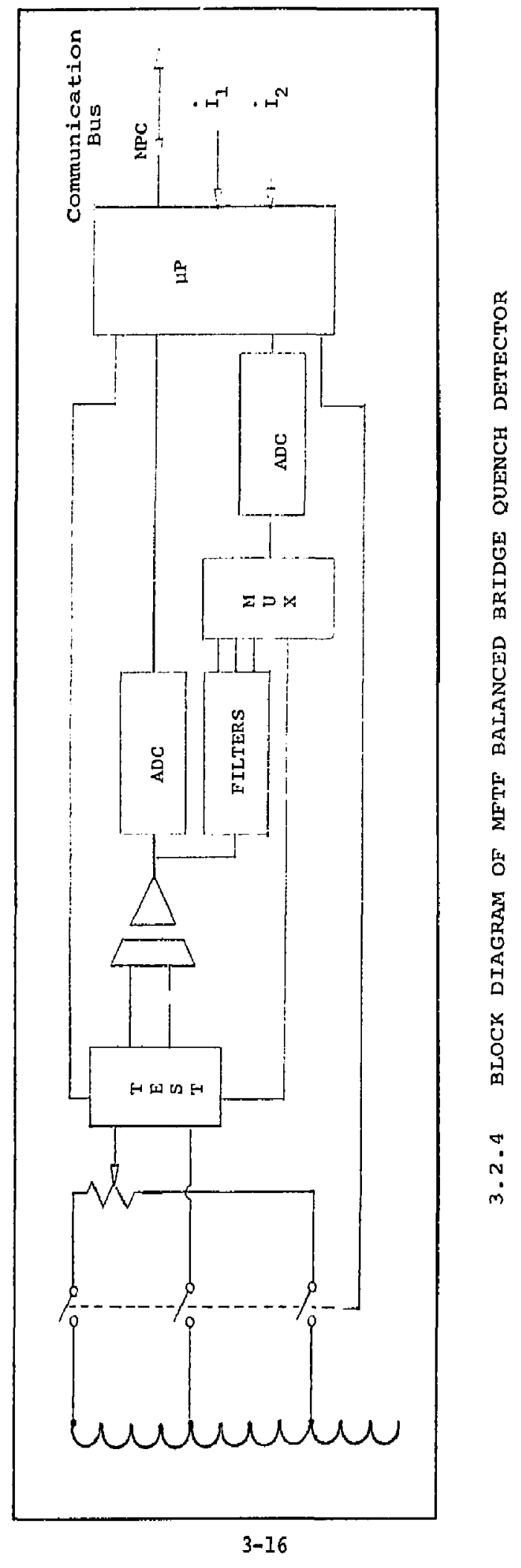




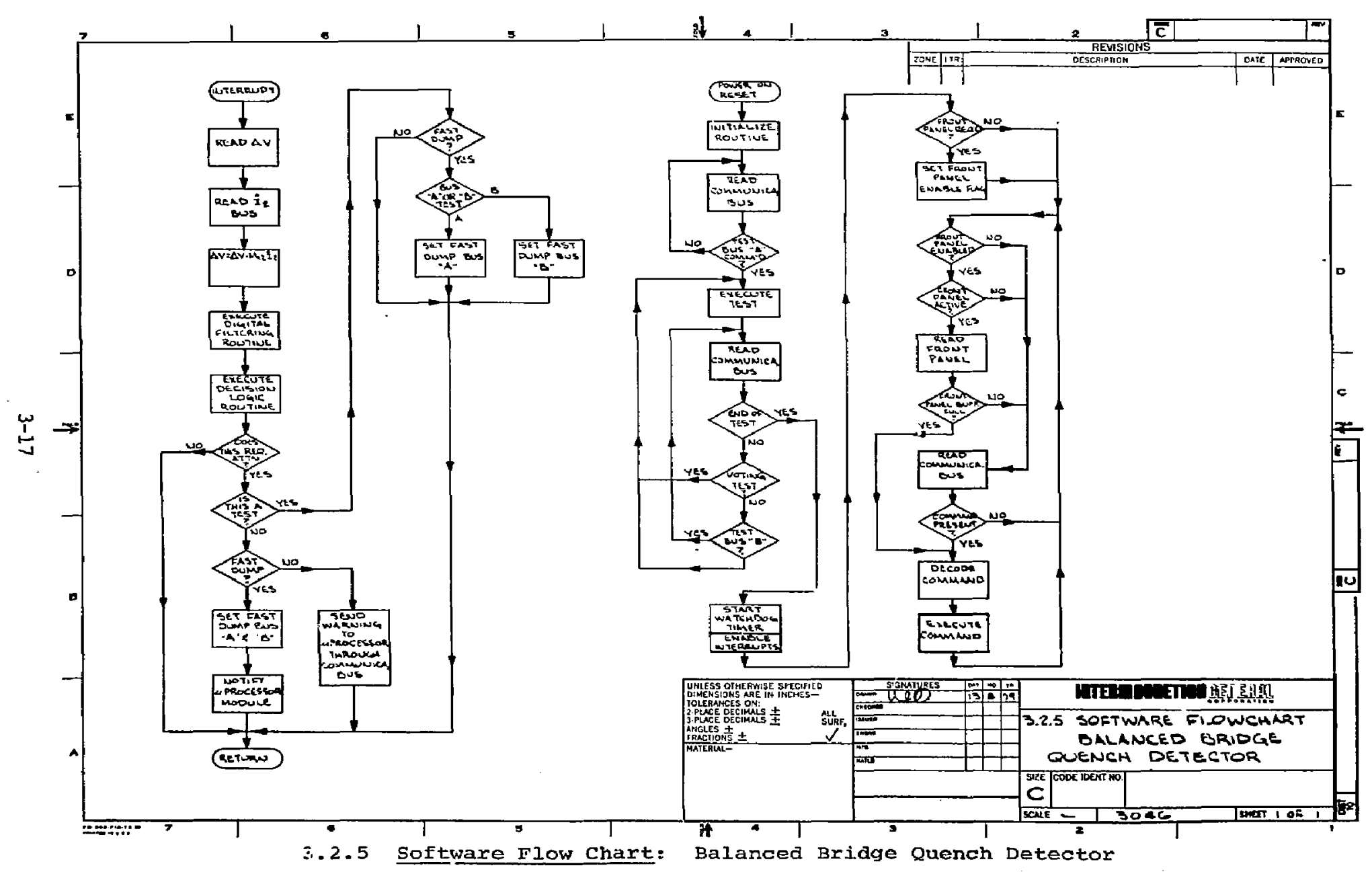




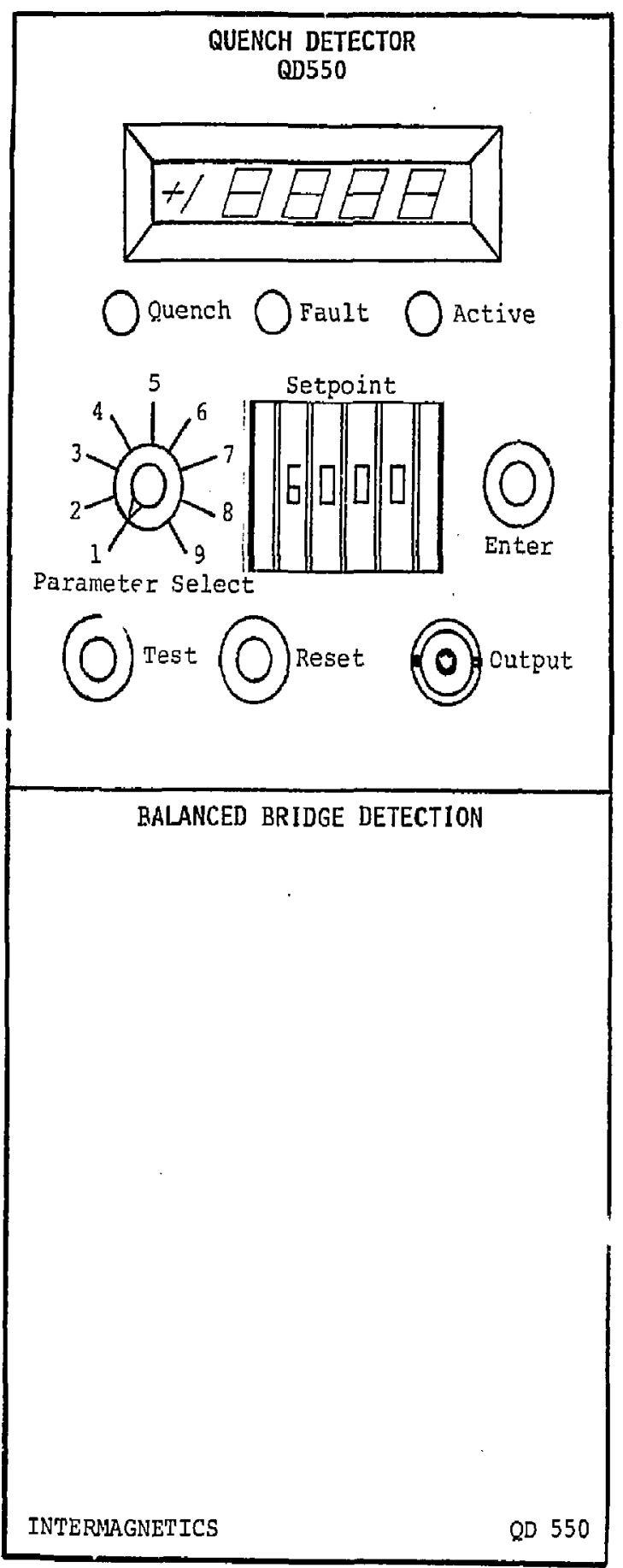

\subsubsection{Front Panel}




\subsection{Current Rate Method}

\subsubsection{Discussion of the Principle}

For a pure inductor the rate of change of current is directly proportional to the voltage across the inductor. This basic relationship can be used to detect a quench. In Figure 3-3 a model for the current rate method is outlined. The resultant signal for $Q_{1 D}$ includes the mutual inductive voltage term $\mathrm{M}_{12}{ }^{\circ}{ }_{2}$, which was computed earlier in section 3.1.3. This of course must be subtracted from $\Delta V$ to give the true quench signal.

The method requires a transducer which gives an output proportioned to the current rate $\dot{I}_{1}$. Current rate transducers can be either a current transformer or a current monitor with a differentiator. The multiplying and subtraction required for this technique can either be done with analog or digital components. Since the signal processing required for $\Delta V$ will be done in software, the scaling and subtraction required for forming $\Delta V$ is efficiencly done with software.

\subsubsection{Description of the Module}

The current rate quench detector module is very similar to the balanced bridye quench detector described in section 3.2. The primary difference is that the current rate module requires an additional input channel from the current rate transducer and eliminates the need for the voltage tap balance network. The current rate transaucer is assumed to be an air core transformer. The module alsc nas an additional output, the current rate it measures and sends to other quench detectors. A block diagram of the module is shown in the next section. The front panel is similar to the balanced bridge in section 3.2.6.

The signal processing algorithm has been described in Section 3.2.3. Ic essentially requires that $M_{12} \dot{I}_{2}$ be subtracted froni the raw quench signal $\Delta V . M_{12}$ is a parameter established by analysis and later verified by experiment before it is burned into ROM. 


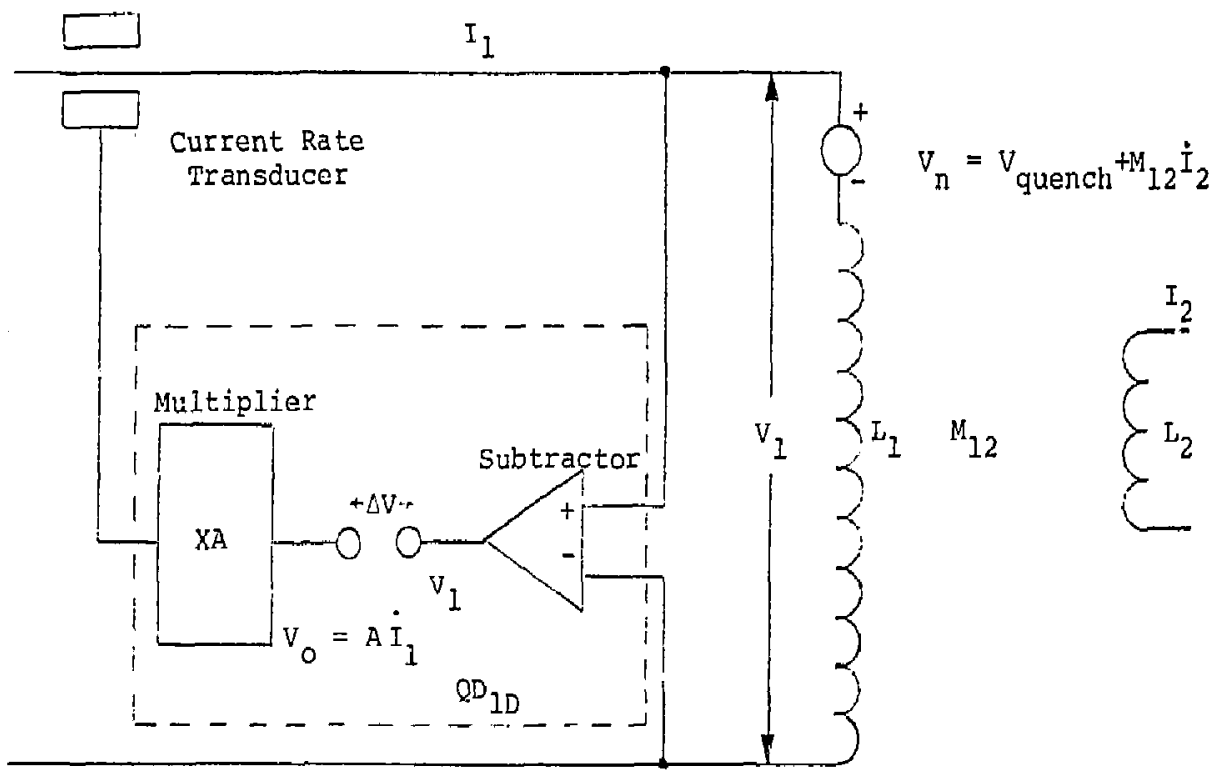

Note: In $Q D_{I D} V_{0}$ is compared to $V_{I}$. At balance $A$ is adjusted so that $v_{0}=V_{1}$. Assuming tre system was balanced when $v_{n}=0$, $A=L_{1}$. When an unbalance occurs

$$
\mathrm{v}_{1}=\mathrm{v}_{\mathrm{n}}+\mathrm{L}_{1} \dot{\mathrm{I}}_{1}
$$

so the signal $\Delta V$ becomes

$$
\begin{aligned}
\Delta v & =V_{\text {quench }}+\mathrm{M}_{12} \dot{\mathrm{I}}_{2}+\mathrm{I}_{1} \dot{\mathrm{I}}_{1}-\mathrm{I}_{1} \dot{\mathrm{I}}_{1} \\
& =\mathrm{V}_{\text {quench }}+\mathrm{M}_{12} \dot{\mathrm{I}}_{2}
\end{aligned}
$$




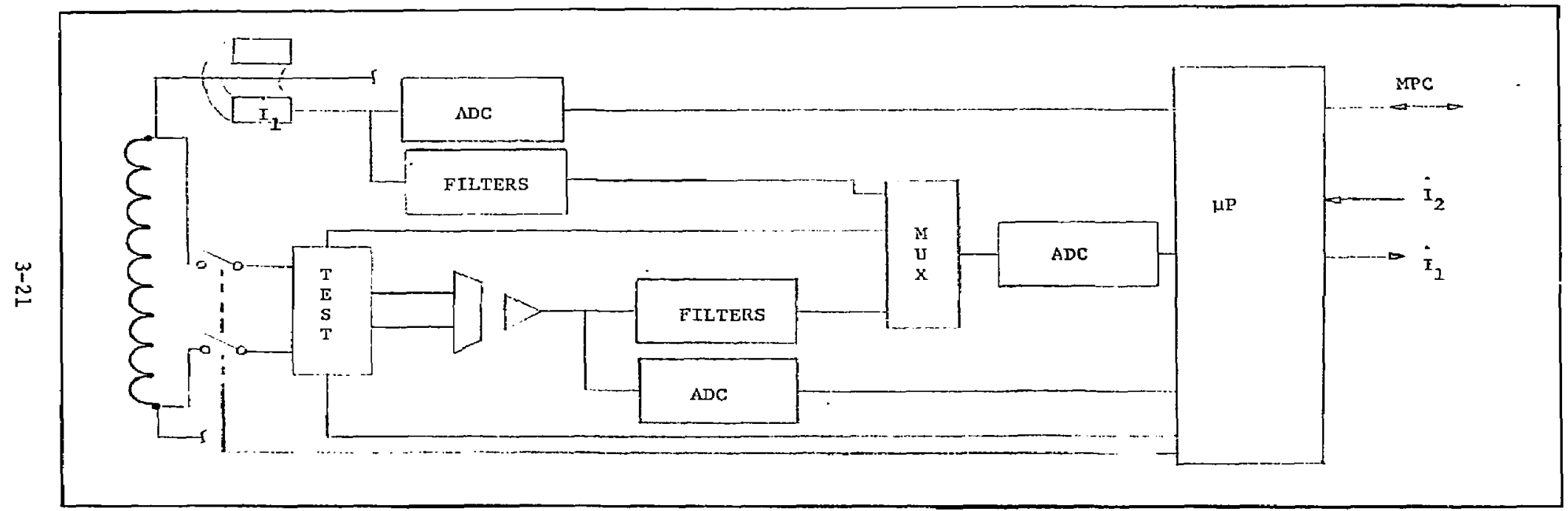

3.3.3 BLOCK DIAGRAM OF LFTF CURRENT RATE QUENCH DETECTOR 


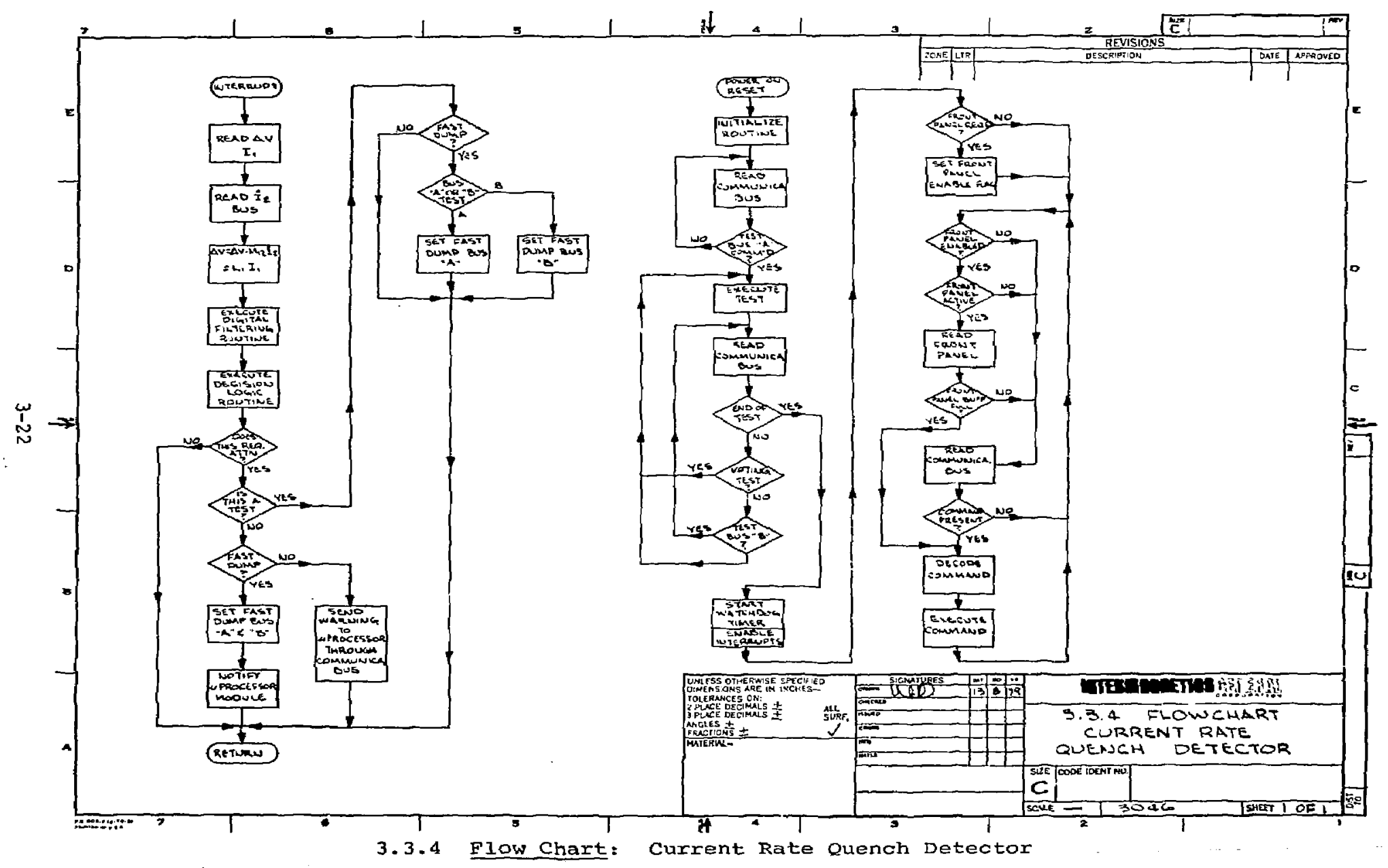


The components and features are almost identical with the balanced bridge quench detector except for the additional output bus carrying the current rate data.

\subsection{Quench Detector Connection}

Fig. 3-4 shows the arrangement recommended for MFTF. In most cases, this arrangement is redundant to three levels. For example, if Q.D. IA fails, Q.D. IC and Q.D. ID will be able to detect a normal zone. Of course, if Q.D. ID or an $\dot{I}$ sensor fails, other quench detectors which rely on $\dot{I}$ information will be handicapped. This situation could be backed up by a redundant $\dot{I}$ detector or by the magnet protection microprocessor computing $\dot{I}$ from current readings from the power supply shunt. Current rate information is also available at the current controller in the current rate set point buffer but the actual current rate may differ (See section 4.8). The correction due to the current rate (I) is not large enough to cause a quench in most quench detectors except $Q_{1 D^{\circ}}$ This can be prevented by adequate quench detector voting logic.

\subsection{Quench Voting}

Additional reliability may be gained by passing fast durnp requests from quench detectors through some decision logic before activating the breakers. The decision logic cannot be too restrictive else if a quench detector fails, a quench would be missed. There is enough redundancy in the proposed connection (Section 3.4) that even if a single quench detector fails, the magnet would survive. Below is a voting table, Table $3-2$, that accommodates single quench detector malfunction without adversely effecting the magnet. By making the decision logic programmable, even multiple quench failures could be tolerated without endangering the magnet. 


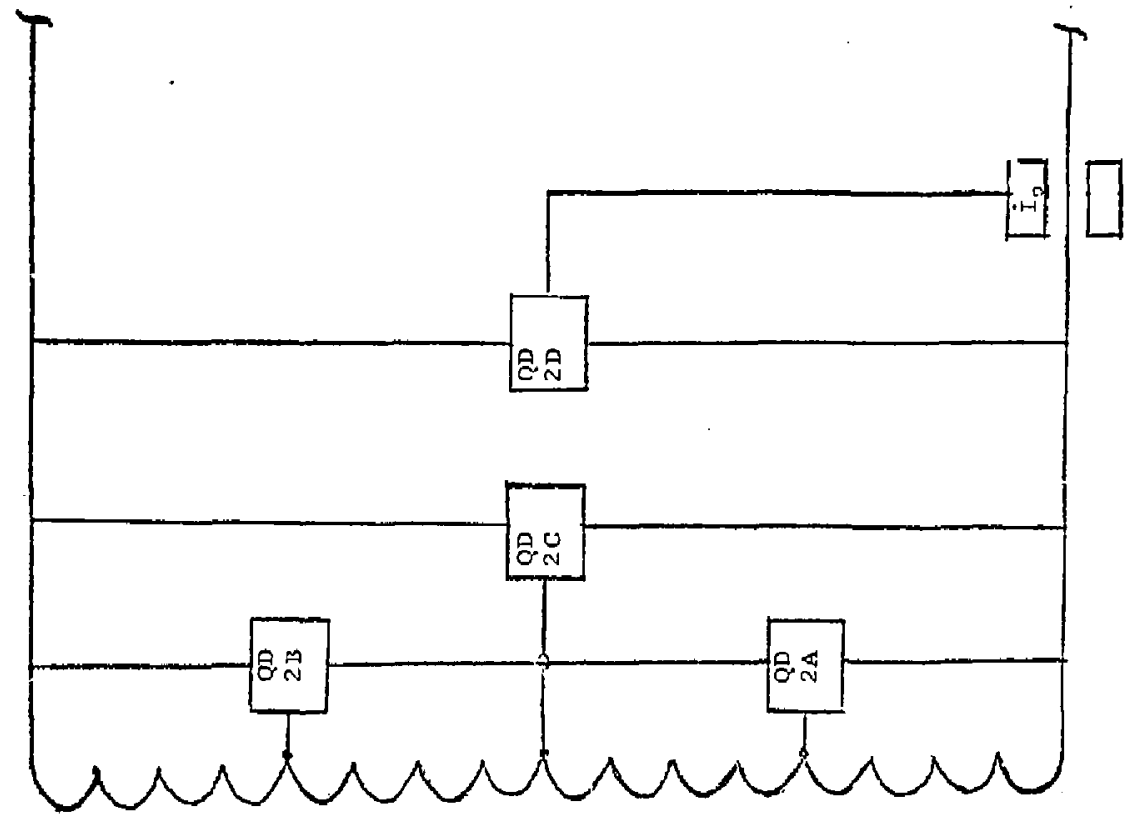

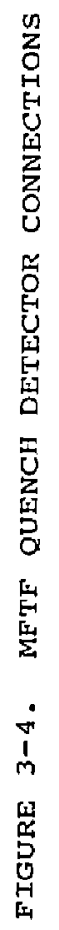


Table 3-2

Proposed Quench Voting Table

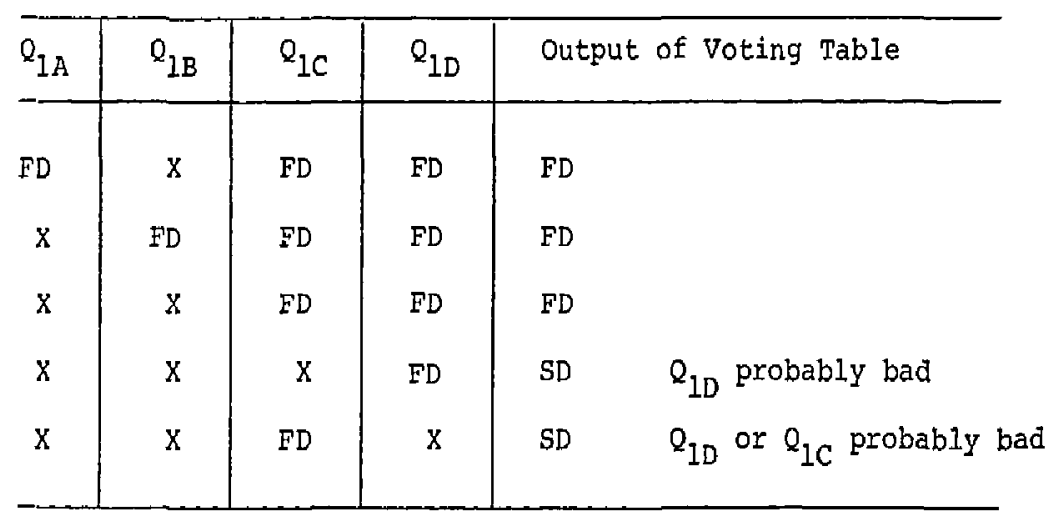

$F D=$ Fast Dump

$\mathrm{ND}=$ No dump

$\mathrm{X}=\mathrm{ND}$ or Quench Missed

$\mathrm{SD}=$ Slow Dump and Alarm 
4.1 $\quad$ Overview

\subsubsection{System Diagram and Instrumentation List}

Figure 4-1 shows a preliminary drawing of the MFTE magnet electronic instrumentation and control system. The drawing includes all ergupment recuired for monitoring and protecting the magnet.

All critical monjtors funnel into the central control cabinet which contains the quench detectors, current controllers and protection modules. Control signals, such as the fast dump busses and power supply current demand signal, fan out from central control cabinet.

Some typical inputs to protection modules include relay position indicators, dump resistor thermostats, vacuum pressure switch contacts, and single threshold outputs from signal conditioners such as the lead voltage monitor. The status of the inputs are indicatei on the front panel of the central control console.

The voltage taps from the magnet enter the central console in the quench detector input relay modules which disconnect the taps in the event of a fast dump. In the relay box, the taps are routed to each quench detector. The balanced bridge quench detectors require three taps, a center tap and two outside taps. This connection is shown in Figure 3-1. The current rate quench detectors require two taps and a separate input from the $\dot{I}$ transducer. The magnet taps into the current rate quench detector originate at the extreme ends of the magnet as shown in Figure 3-3 processor module. There are two separate fast dump output busses from each quench detector that feed into the quench detector voting logic module. Fast dump signals are passed through the voting logic module and are sent to the breaker driver interface module which controls all of high current circuit breakers. In the breaker driver module, additional fast dump and slow dump command signals from the input indicators merge with those from the quench detector voting logic and determine the combination of 


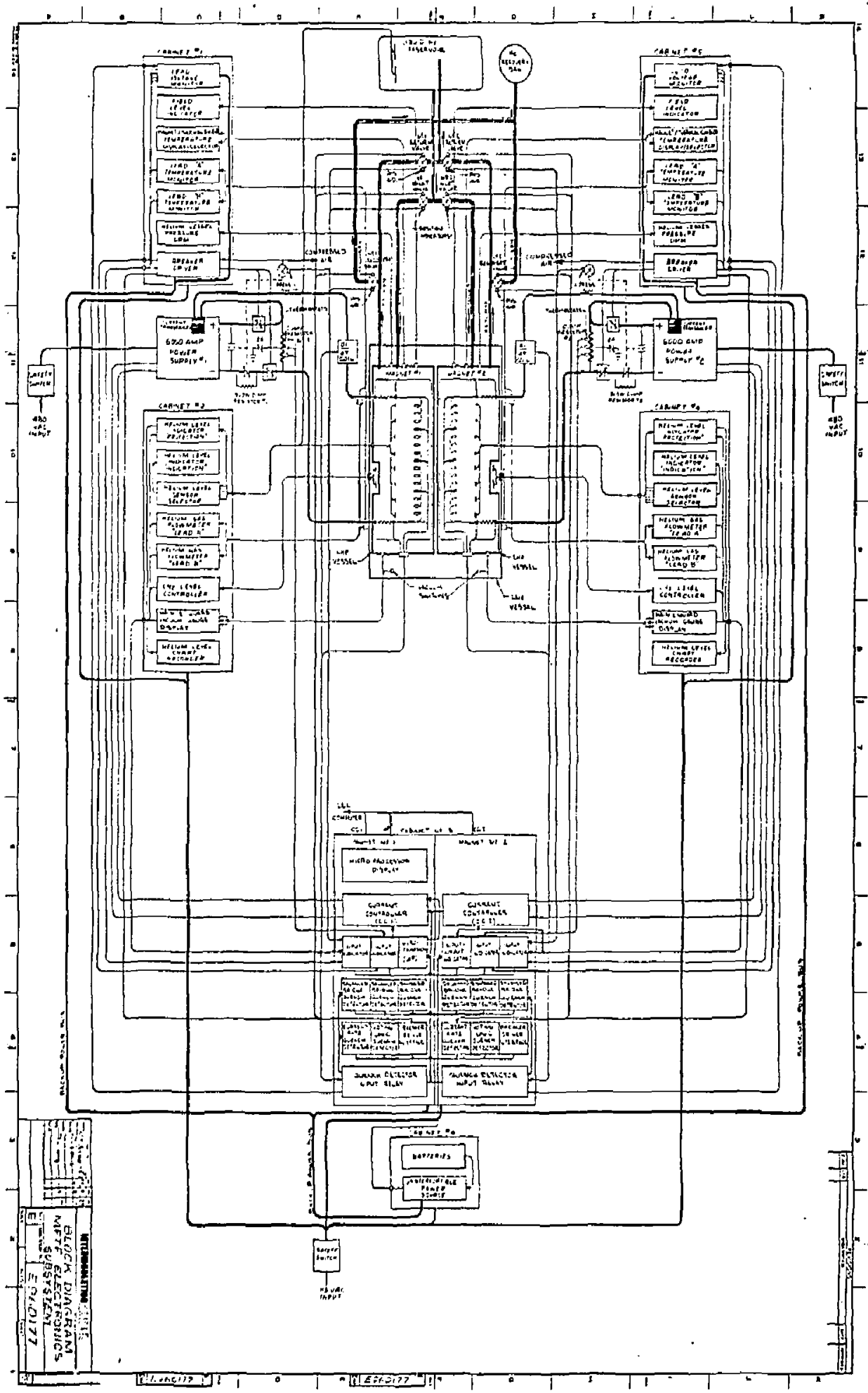




\section{TABLE 4-1}

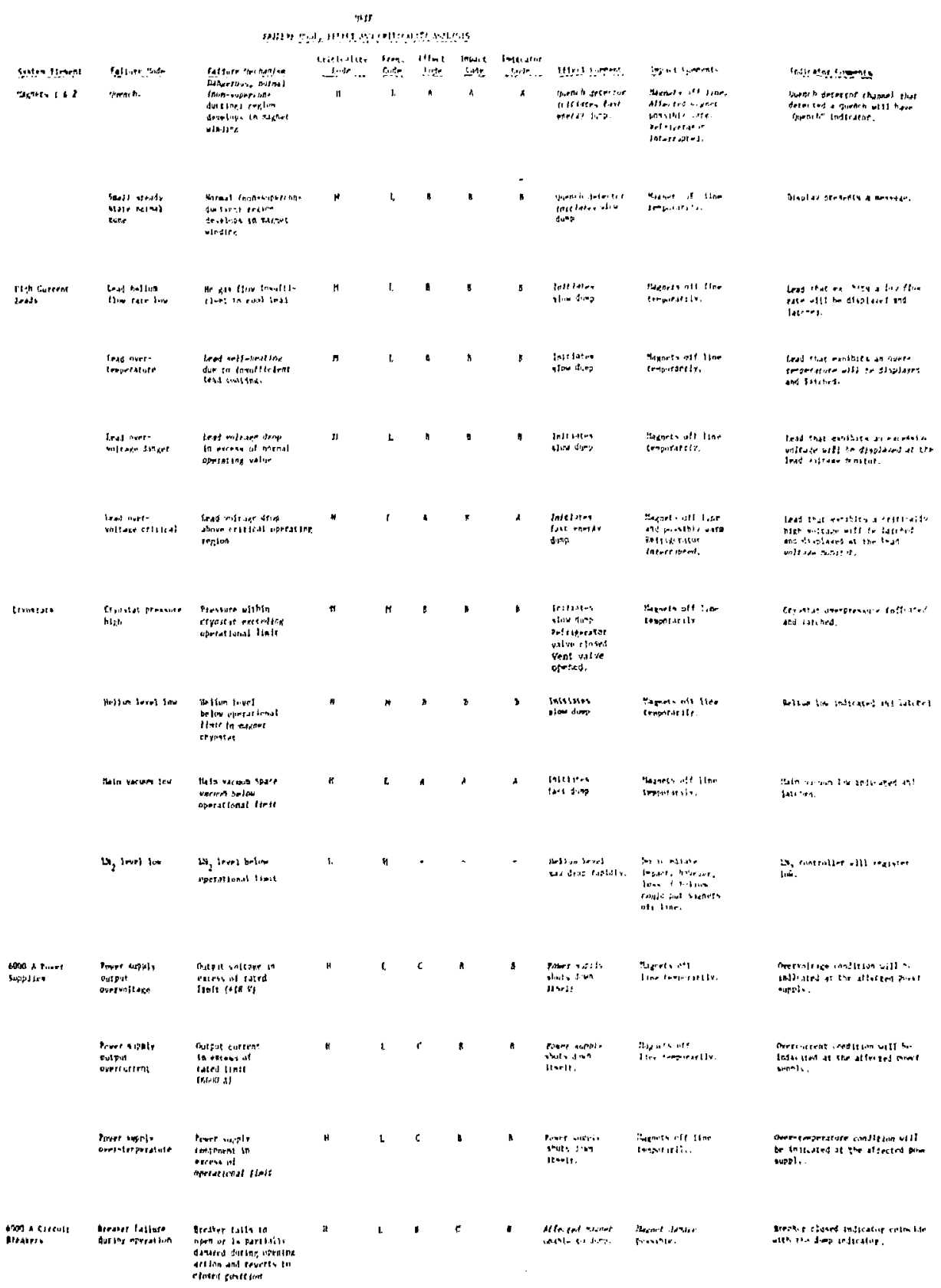




\section{TABLE 4-1 (continued)}

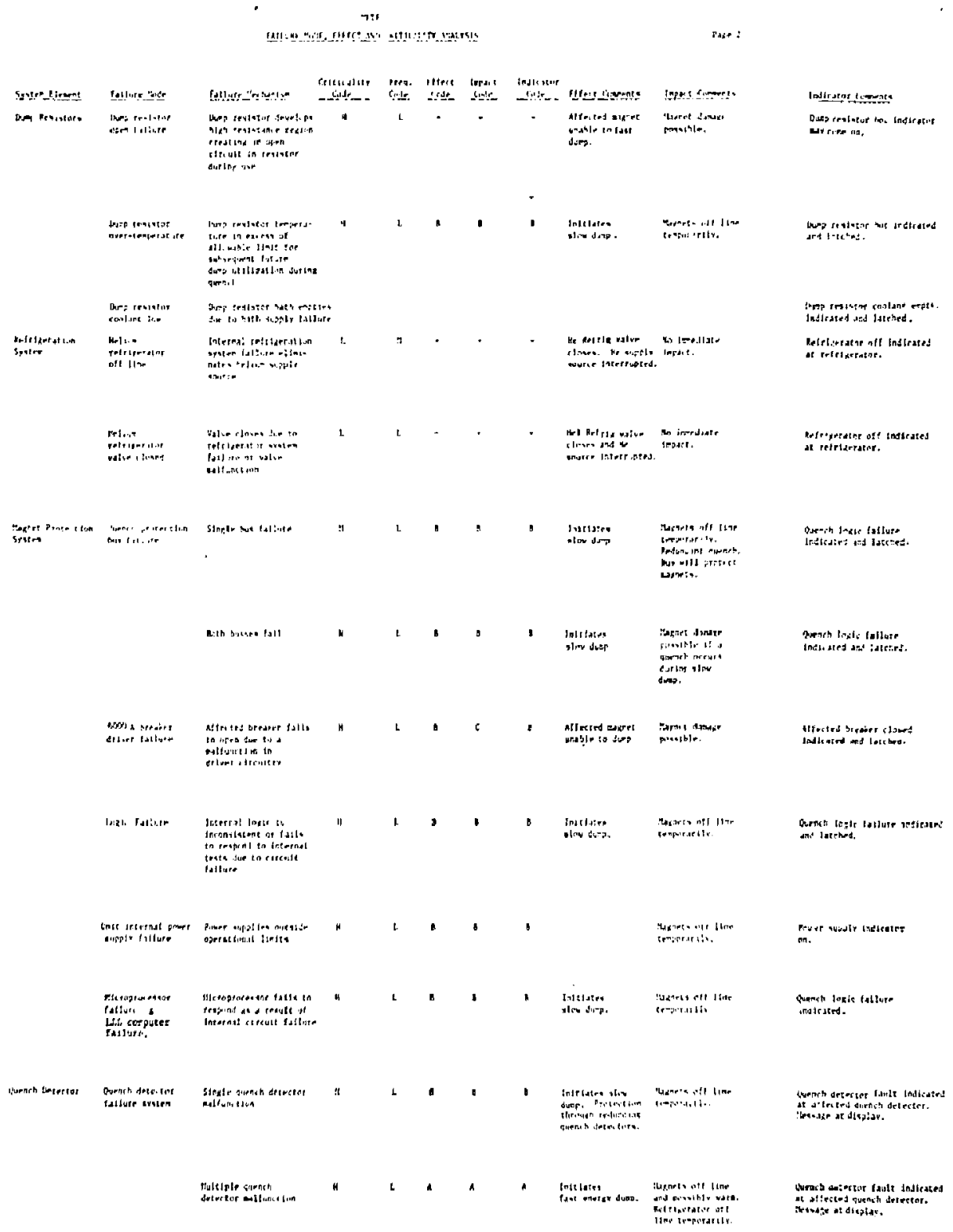




\section{TABLE 4-1 (Continued)}

\begin{tabular}{|c|c|c|c|c|c|c|c|c|c|c|}
\hline \multirow[b]{2}{*}{ st:ten Netrent } & \multirow[b]{2}{*}{ 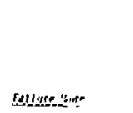 } & 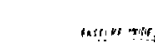 & דיt & $\therefore+1 !$ & 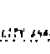 & & \multicolumn{3}{|r|}{$x_{n, 1}=1$} & \multirow[b]{2}{*}{ 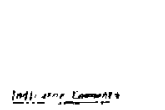 } \\
\hline & & 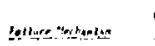 & 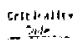 & $\lim _{i \rightarrow 0}$ & mont & 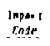 & 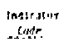 & Hents:senten & 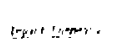 & \\
\hline \multirow[t]{3}{*}{$\begin{array}{l}\text { litility hine } \\
\text { nome }\end{array}$} & Sto var lowe $[+11$ & 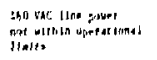 & $:$ & n & с & 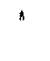 & 8 & 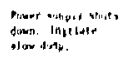 & 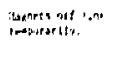 & 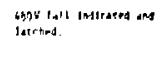 \\
\hline & 170 ing Pere fat1 & 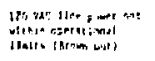 & " & r & - & - & $=$ & 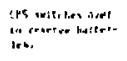 & smen & 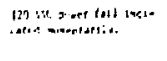 \\
\hline & & 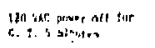 & $n$ & H & - & $B$ & $\Delta$ & 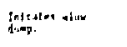 & inter & 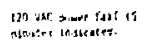 \\
\hline \multirow[t]{2}{*}{$\begin{array}{l}\text { Eninger rupe ints } \\
\text { Poved soutre }\end{array}$} & 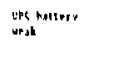 & 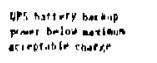 & $*$ & t. & $=$ & $n$ & - & 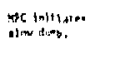 & 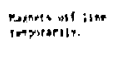 & 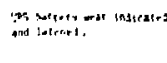 \\
\hline & 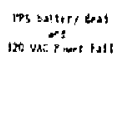 & 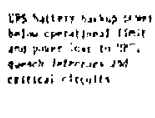 & n & 4 & $A$ & $A$ & $A$ & 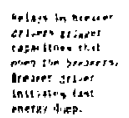 & 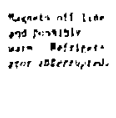 & III IVIestints: \\
\hline
\end{tabular}

EnTyits.

EFIIT Lith a

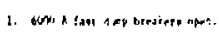

2. Lexnet cutrent trancion troa

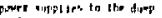
imaterss.

1. Antrigeration value thave

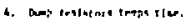

3. Ir Ilem levrits an drup.

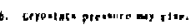

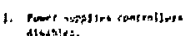

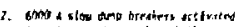

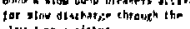

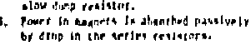

timat: rrit:

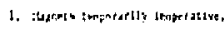

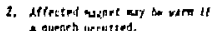

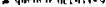

3. Ventigerstor vilue ta clareit.

4. Vent rativ opertirt.

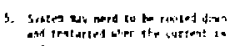

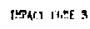

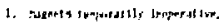

2. Pows sipgly reatroll pry

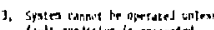

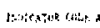

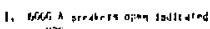

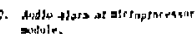

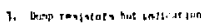

privitile.

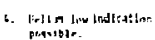

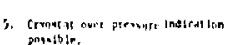

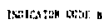

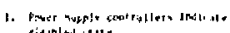

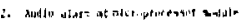

Entar ats c.

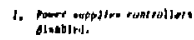

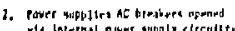

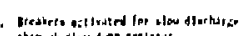

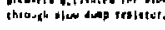

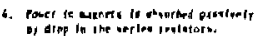

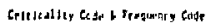

in - Il, th

A. Houstim 17ate cort $\mathrm{c}$

d. Pinotitie mant dander

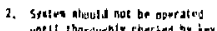
uneit thar 
relays to be opened or closed. In addition, the breaker driver module contains inhibit gates and front panel controls that allow testing to occur with or without triggering the circuit breakers. The fast dump busses are optically coupled to the breaker driver circuits which activate the coils of the circuit breakers.

All protection modules such as the input indicators, quench voting logic, and breaker driver interface share a common IEEE-488 interface which links them to the microprocessor module.

The central control cabinet also contains the current controllers which are interfaced to the input indicator and to the microprocessor module. The interface to the input indicator module is used as a power supply interlock. If an alarm appears at the input iniicator the current controllers are forced to ramp to zero and cannot be operated until the alarm is cleared.

The interface from the LLI computer enters at the control console and interfaces separately to the current controller and microprocessor module. Conmunication from the LIL computer to the current controller is kept private so that no conflict in control between the microprocessor module and the LI,L computer is possible. 


\subsubsection{Front Panel Layout and List of Modules}

Figure 4-2 shows the front panel of the magnet protection control console. On the top of the console is mounted a 32 character display which is used to prompt the operator as to the status of the macnet system. The display is driven by the Microprocessor Module through the IEEE-488 bus.

The current controllers are mounted just below the display within reach of the operator. Under the current controller are mounted a group of modules which together comprise the magnet protection system.

The Microprocessor Module is the hub of the protection system. It controls communication and coordinates testing between modules. The input indict'sr panels indicate status on alarm conditions. The breaker ariv urs interface module and quench voting logic moaule coordinate fast dump requests from the quench detectors. The quench detectors are mounted below the display modules since thiy afe stand alone devices and rarely need attention.

A complete list of protection modules recommended by IGC is given in Table 4-2. 
MFPF MAGNET EROTESTION CONSOLE

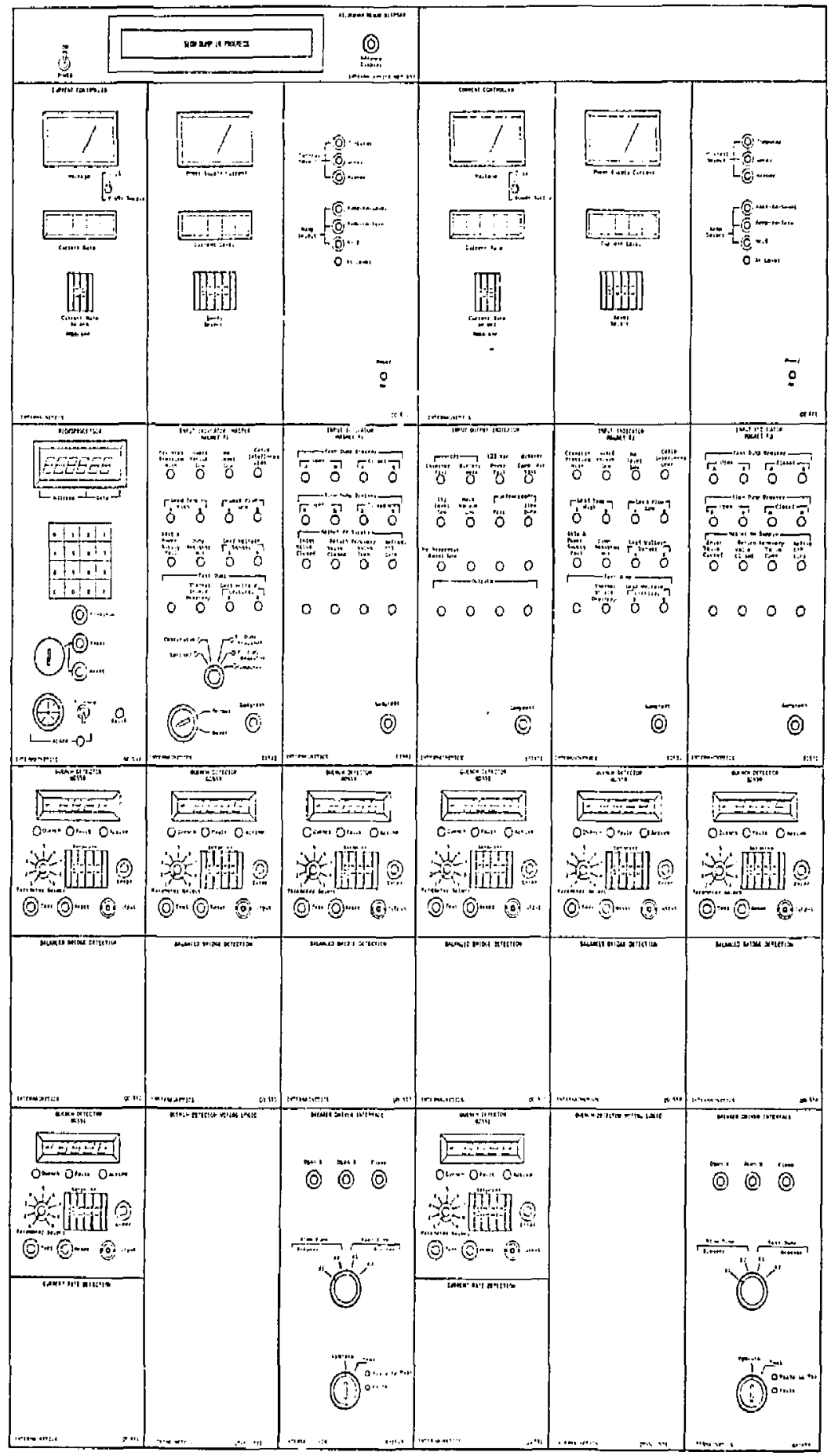


LIST OF PROTECTION MODULES RECOMMENDED FOR MF'TF

DEVICE ITLE
Microprocessor
Input Indicator (Master)
Input Indicator
Input-Output Indicator
Quench Detector (Voltage Balance)
Quench Detector (Current Rate)
Quench Detector Voting Logic
Breaker Driver Interface
Microprocessor Display
Quench Detector Input Relay
Current Controller

IGC

MODEL

MP 500

II 501

II 502

IOI 503

QD 550

QD 551

QDVL 504

BDI 505

MPD 600

QDIR 601

CC 602 


\section{1 .3}

System Operation

The magnet protection system works as follows. When the system is first powered up the microprocessor module takes control and locks up the current controller by forcing it to ramp to zero (at power up it will be at zero anyway) and does not allow the operator or the LLL computer to energize the magnet until the system is completely checked out. The microprocessor prompts each quench detector to begin a self test cycle. Upon the completion of each test, the microprocessor expects to receive a "test pass" response from each quench detector. The microprocessor then requests the quench detectors to toggle the individual fast dump busses in all combinations while at the same time inhibiting fast dump circuit breakers from opening. This allows the microprocessor module to test all. circuitry up to the breaker driver interface module including the quench detector voting logic. The breaker driver interface module is wired so that only one fast dump bus can be inhibited at a time. (Note that there are two fast dump busses, one for redundancy.) This prevents the microprocessor from inadvertently commanding the breaker driver interface to gate both fast dump busses off, leaving the magnet dangerously unprotected.

If the quench detector passes the initial power up tests, the microprocessor asks the operator if he would like to manually activate the large circuit breakers. If the operator would like to perform a test, he must turn the keylock switch on the face of the breaker driver module to the test position. The microprocessor guides the operator through the test using messages at the display. The test is monitored by the microprocessor and error messages appear if the test malfunctions or if the operator makes a mistake.

If all tests pass, the microprocessor unlocks the current controller 
so the power supply may be operated from the console or the computer. Meanwile, the microprocessor spends most of its time polling the quench detectors to see if they are active.

If a problem exists, the microprocessor switches on the front panel audio and visual alarms to get the operator's attention and sends a message to the LIL computer describing the nature of the problem. In the event of a quench or fast dump, the microprocessor records the current in the magnet as a function of time and other parameters of interest during a quench. These parameters are stored in the microprocessor's memory and may be read out through the front panel display or transmitted to the LIL computer.

Status and alarm conditions in the magnet system are trapped by tive input indicator modules. The inputs are wired directly to the dump busses and will cause a dump immediately if an alarm occurs. The microprocessor monitors these inputs but does not react to them. This takes the microprocessor module out of the critical protection path.

For critical paths like the fast dump busses, two busses are carried from the guench detector. As explained be:tore, one bus is for redundancy. The redundancy is maintained in the circuitry as well. The quench detector voting logic module, the breaker driver interface module, and the breaker driver have completely independent circuits, one dedicated to each bus. The fast dump signal propagates down each critical bus through no common components.

A special purpose module, an input/output indicator, is also included in the system. The module's outputs are used to open refrigerator vent valves and close refrigerator return valves during a fast dump. 
Finally, the proposed system also reacts to prevent internal module power failure. Some critical modules like the input indicators, breaker driver module, and the quench detector voting logic contain provisions for backup power input in case power to the logic fails due to either a power supply problem or a facility power failure. The input power required is DC and automatically switches in through diodes when the logic voltage drops below an operational level. Voltage threshold monitors which monitor the module power are included in each module and are connected to the slow dump bus. The backup power is provided by batteries and inverters which are monitored by the protection system. If all power fails, including the backup power, the protection system activates a fast dump in a last attempt to protect the magnet. 
The magnets should be under the protective control of supporting electronics. These pieces of equipment provide magnet protection in the form of a slow dump or fast dump of the magnet energy. A slow dump of magnet energy should be initiated for any of the following conditions.

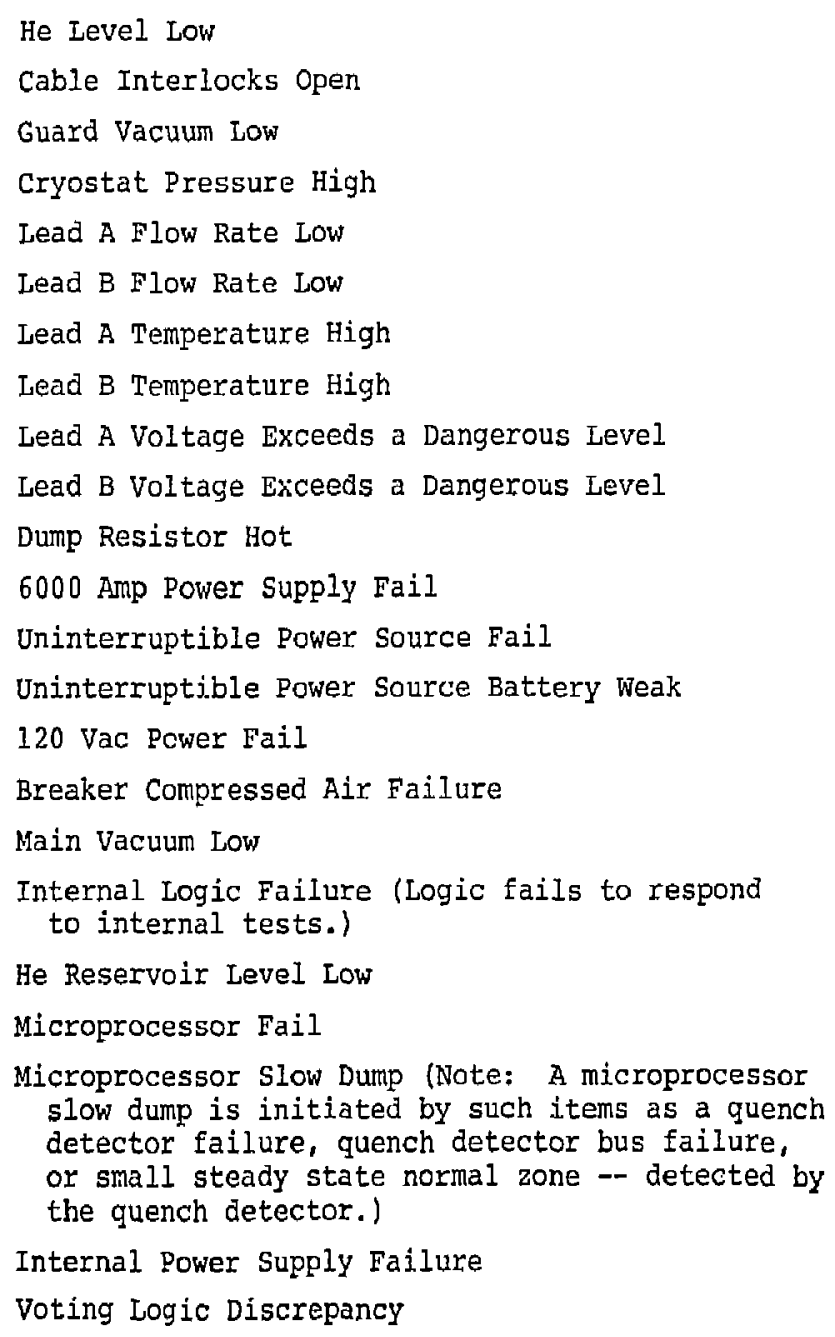


A fast dump of magnet energy should be required if any of the following conditions occur.

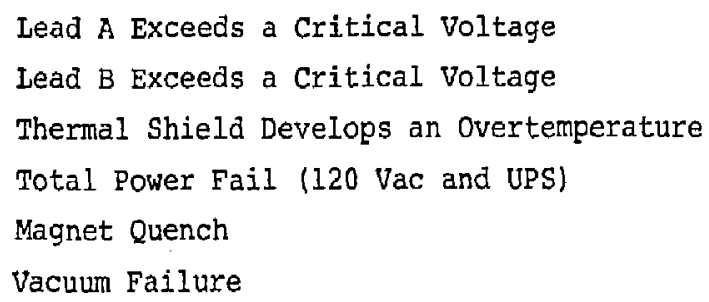

In Table 4-1, a complete failure mode and criticality analysis (FMECA) is presented for the NFTF magnet system. 


\subsection{Microprocessor Module}

\subsubsection{Description}

The microprocessor can be programmed for a variety of functions. Front panel program changes can be made using the keyboard with the address-data display when the keylock switch is in the enter/ reset position. Bidirectional communication between the microprocessor and magnet protection system is accomplished via an IEEE- 488 bus. Communication between the microprocessor and the LLI computer is through a separate interface bus. The module can be interfaced to an external 32 character alphanumeric display unit through the IEEE-488 bus. A programmable front panel audio/ visual alarm can be programmed to alert the operator of potentially harmful conditions.

\section{Specifications}

Display:

4 Hex characters, 2 address +2 data

Keyboard:

Hexadecimal

Input/Output:

I/O IEEE- 488 bus

Serial I/O port with 20 ma current loop interface LLL computer bus

Power:

$115 \mathrm{VAC}, 1 \mathrm{~A}$

$12 \mathrm{VDC}, 5 \mathrm{~A}$ Backup 


\subsubsection{Front Panel}

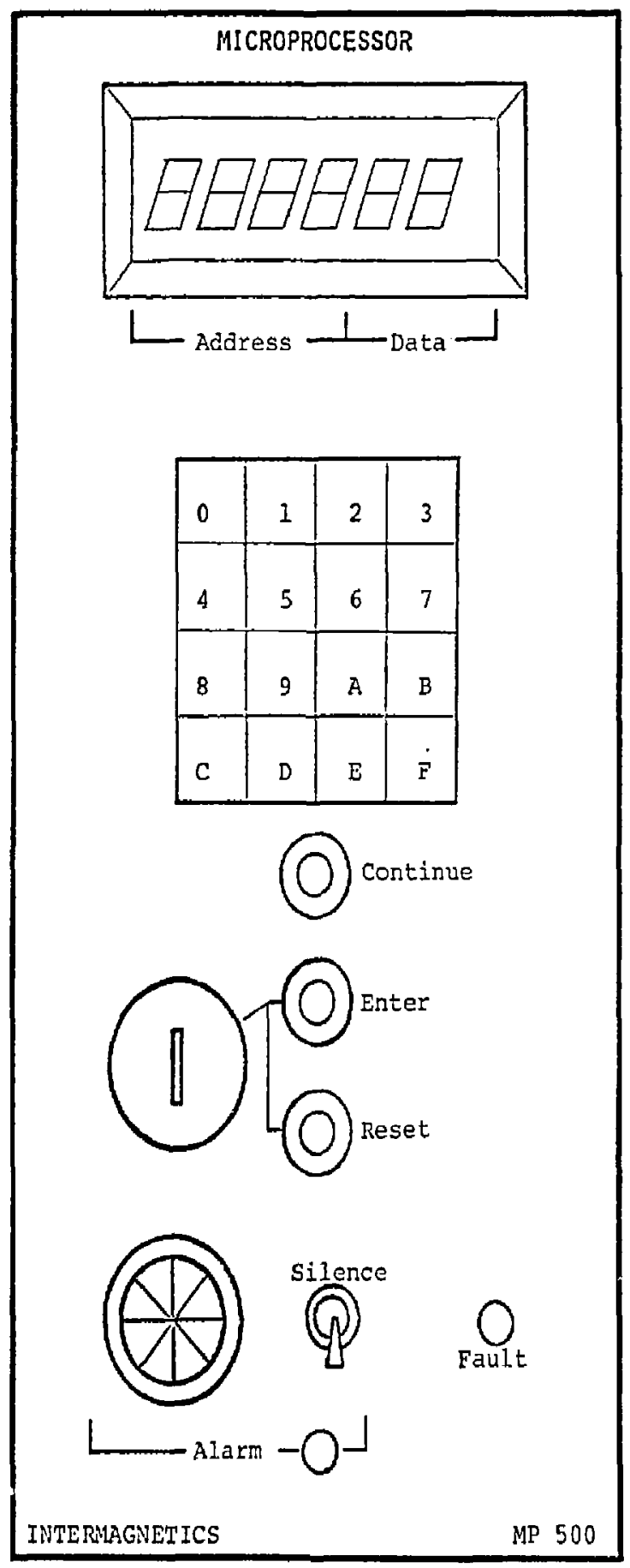


4.3. 3

Block Diagram

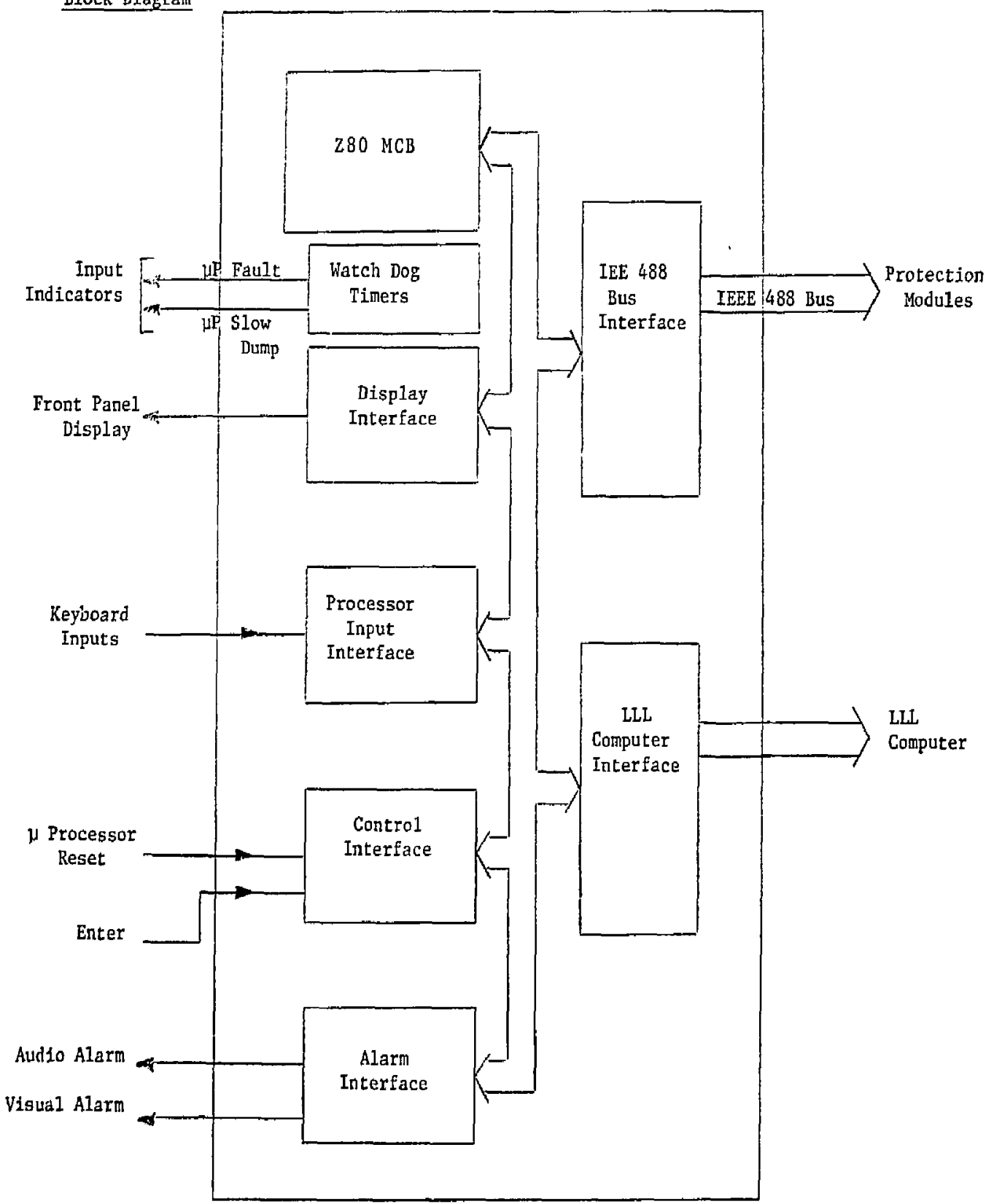




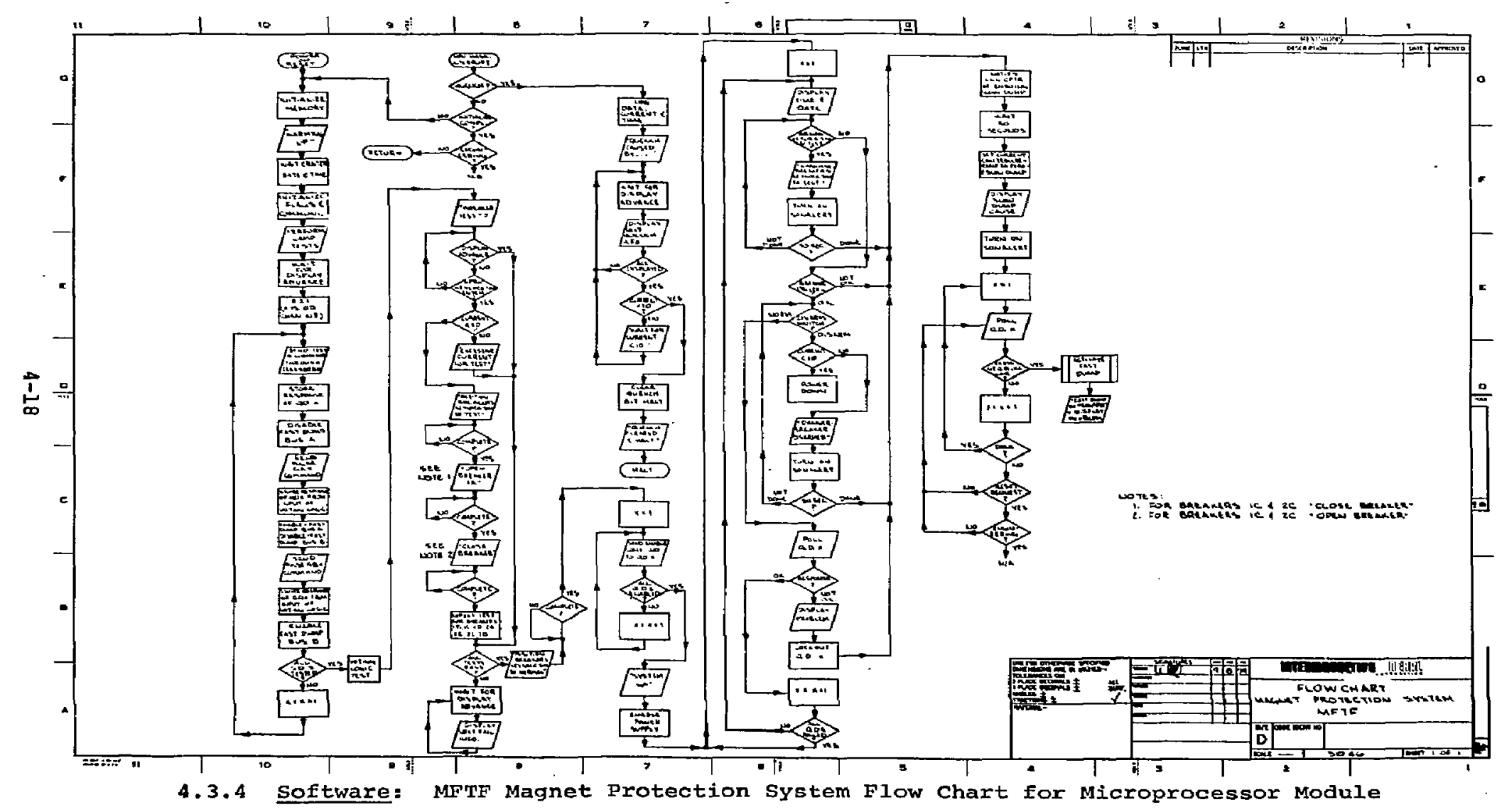




\subsubsection{Description}

The general purpose input indicator device is used to display the status or alarm conditions of a magnet system. Outputs are provided for interface to a magnet protection systen. The input indicator has provisions for inputting and displaying 16 signals. Display mode is selected with a five-position switch.* The modes are as follows:

- Latched - all incoming signals are stored.

- Continuous - incoming signals are samples once a second.

- Slow Dump Snapshot - input states when the slow dump occurred are latched.

- Fast Dump Snapshot - input states when the fast dump signal occurs are stored.

- The fifth position of the mode selection switch is Computer control, whereby remote mode selection is allowed through the IEEE-488 bus.

Indicator lights denote the display mode selected either by the external computer control or by manual selection when not in computer control. Outputs are provided for Fast Dump and Slow Dump signals, which are wired to inputs requiring protective action. These outputs can be bussed to additional input indicator modules allowing common connection and operation of all modules. The keylock switch provides selection between normal operation and the reset condition.* A single reset pulse is generated when the reset switch is initially engaged, cancelling all alarms, then resuming normal operation immediately. The keylock switch must be returned to the normal position before a subsequent

* Where multiple input indicator modules are used together, these switches can be housed in one master module only and eliminated from the other modules. All other input indicator modules respond to the master control. 
reset is allowed.

The unit is also programmable via hardwire connections. For example, any input may be wired to activate the slow ramp down bus, the fast ramp down bus, or if no action is required, the input can be left without being connected to any bus. All inputs are prewired into the IEEE-488 interface.

A unique feature of the module is its extremely high noise immunity. The signals are optically coupled to the logic providing greater than $20 \mathrm{~V} / \mathrm{ns}$ common mode transient noise immunity. In addition, each input is sampled only once a second to reduce the possibility of spurious noise activating critical busses.

The front panel of the module is shown in section 4.4.2. 


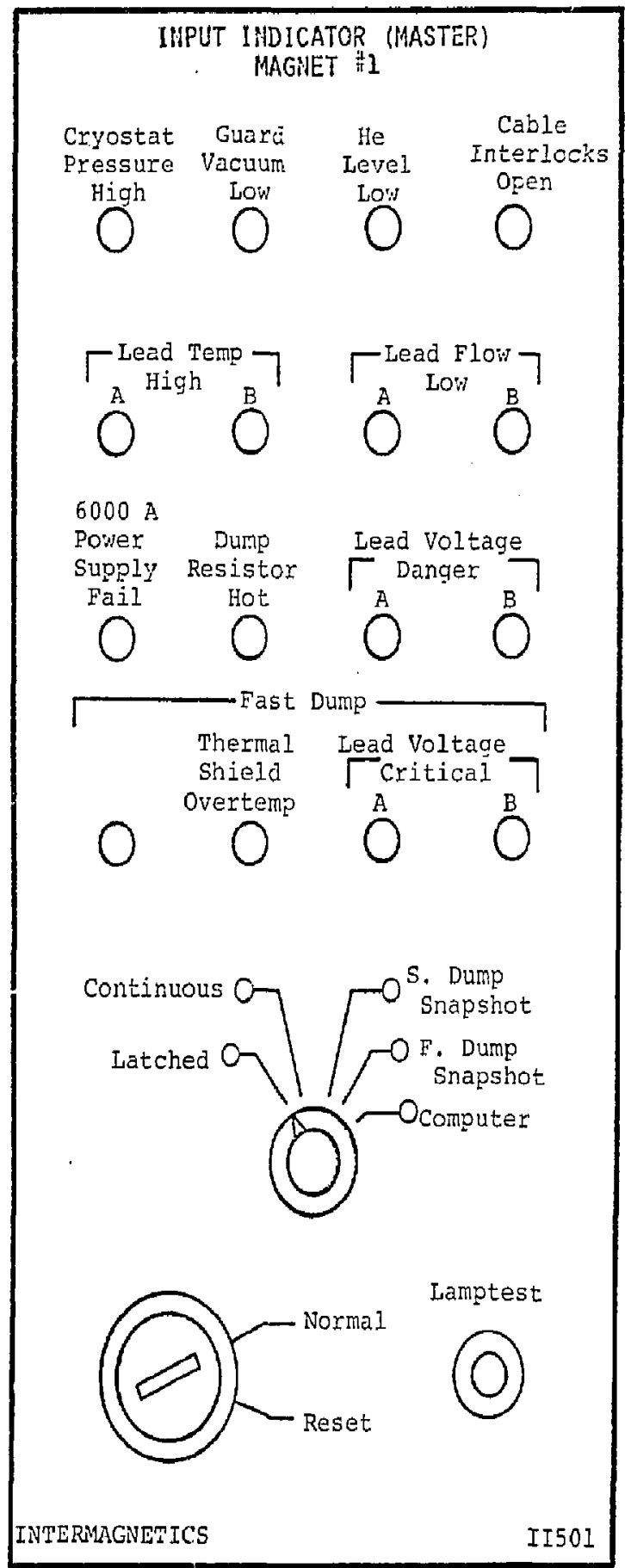




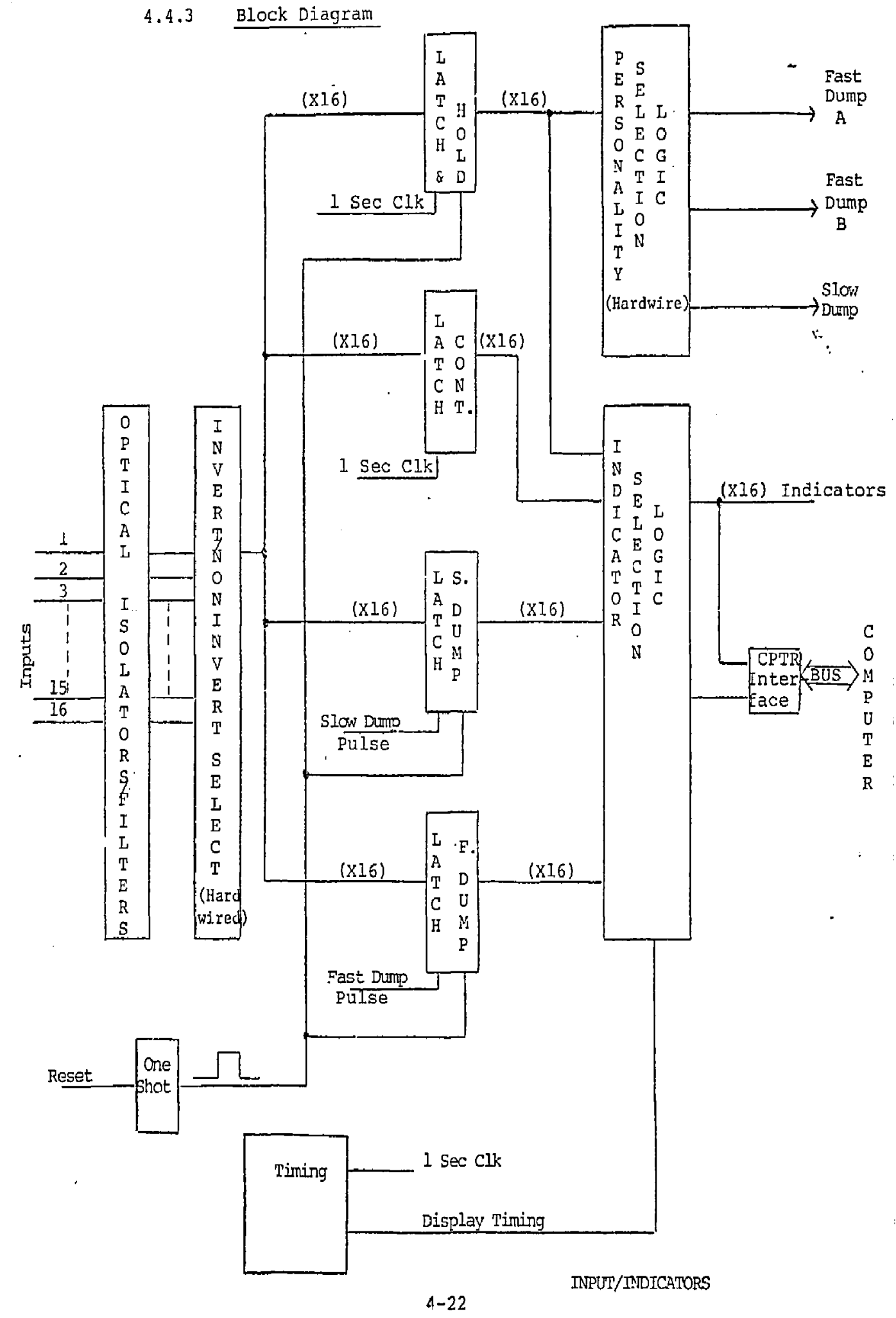




\section{Specifications}

Signal Input: provisions for inputting 16 normally open or normally closed relay contacts or transistor switches. All inputs are optically coupled for optimum noise immunity and are interfaced to an IEEE- 488 bus.

Outputs:

Protection: 3 Busses: $\overline{\text { Dump } A}$ Dump $B$

Internal Buffers

$$
\text { Slow Dump }
$$

Latch and Hold: store all incoming signals

Continuous: sample incoming signals once per second.

Slow Dump: stores irput status when a slow dump occurs.

Fast Dump: stores input status when a fast dump occurs.

\section{programmable Features (Hardwire Connections)}

Invert/Non-invert selection of N.O, and N.C. input sodrces.

Inputs requiring protective action can be connected

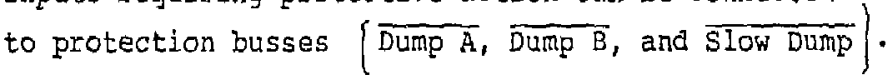
Inputs not requiring protective action would not be connected to the protection busses, but their status would be indicated and sent to the IEEE-48B bus.

Input Power

115 Vac, $1 \mathrm{~A}$

\section{Backup power Input $12 \mathrm{~V}, 5 \mathrm{~A}$}

(This may be reguired for cxitical application when the input/indicators module must be powered by batteries in the suent. of a power failure.) 


\subsection{IGC Breaker Driver Interface Module}

\subsubsection{Description}

The breaker driver interface is used for digital control of the breaker circuitry. The primary function is to permit automatic testing of quench detectors, quench detector voting logic, and fast dump busses. Another function is to permit manual testing of the unit, the breaker drivers, and the breakers from the front panel while the magnet is not in operation. The keylock switch must be in the test position with the ready-to-test light on before one can proceed with manual testing. Slow dump and fast dump inputs from the quench detector voting logic and input indicators are used to control the breaker drivers during magnet operation.

\section{Specifications}

$$
\begin{aligned}
& \text { Inputs: Fast Dump A } \\
& \text { Fast Dump B } \\
& \text { Slow Dump }
\end{aligned}
$$

Outputs: TTL Breaker Driver Busses. These signals activate the breaker driver units which open and close the breakers either during tests or in response to alarm conditions.

Computer Interface: IEEE-498 Bus

Power: $115 \mathrm{Vac}, 1 \mathrm{~A}$ - Backup $12 \mathrm{VDC}, 5 \mathrm{~A}$ 
4.5 .2

BREARER DRIVER INTERFACE

Open A Open B Close

(O)

(a)

(a)

$\Gamma_{\text {Breaker }}^{\text {Slow Dump }} \sqrt[\text { Fast Dump }]{\text { Breaker }}$

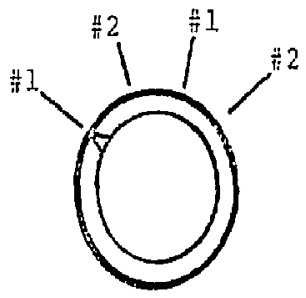

operate

Test

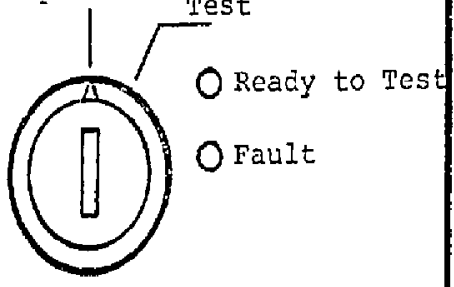




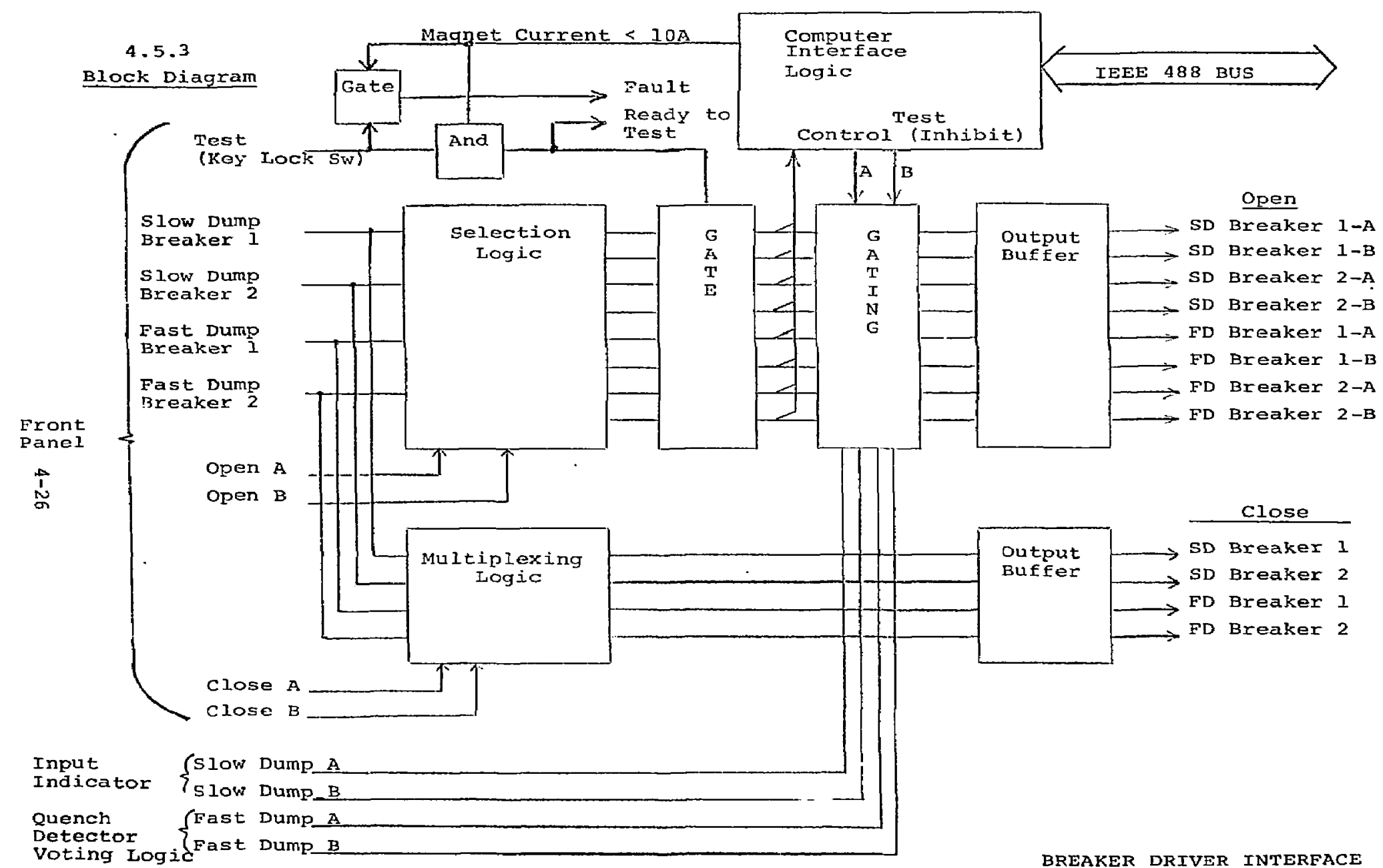

Voting Logid Fast Dump B 


\subsection{IGC Quench Detector Voting Logic Module}

\subsubsection{Description}

The function of the quench detector voting logic module is to trigger the fast dump busses when a programmed combination of input signals appears on the quench detector busses (indicative of quench detected in the superconducting magnet). Any combination of inputs for four quench detectors can be hardwire programmed in the voting logic section. Inputs for quench detectors are also transferred to the IEEE 488 bus for microprocessor monitoring. This provides the ability for greater system reliability by avoiding hasty response to momentary or false quench conditions.

\section{Specifications:}

Inputs: Quench Detector Fast Dump A, Fast Dump B

Outputs: Fast Dump Bus A, Fast Dump Bus B

I/O: $\quad$ IEEE 488 Bus

Power: $115 \mathrm{Vac}, 1 \mathrm{~A}$ - Backup: $12 \mathrm{VDC}, 5 \mathrm{~A}$ 


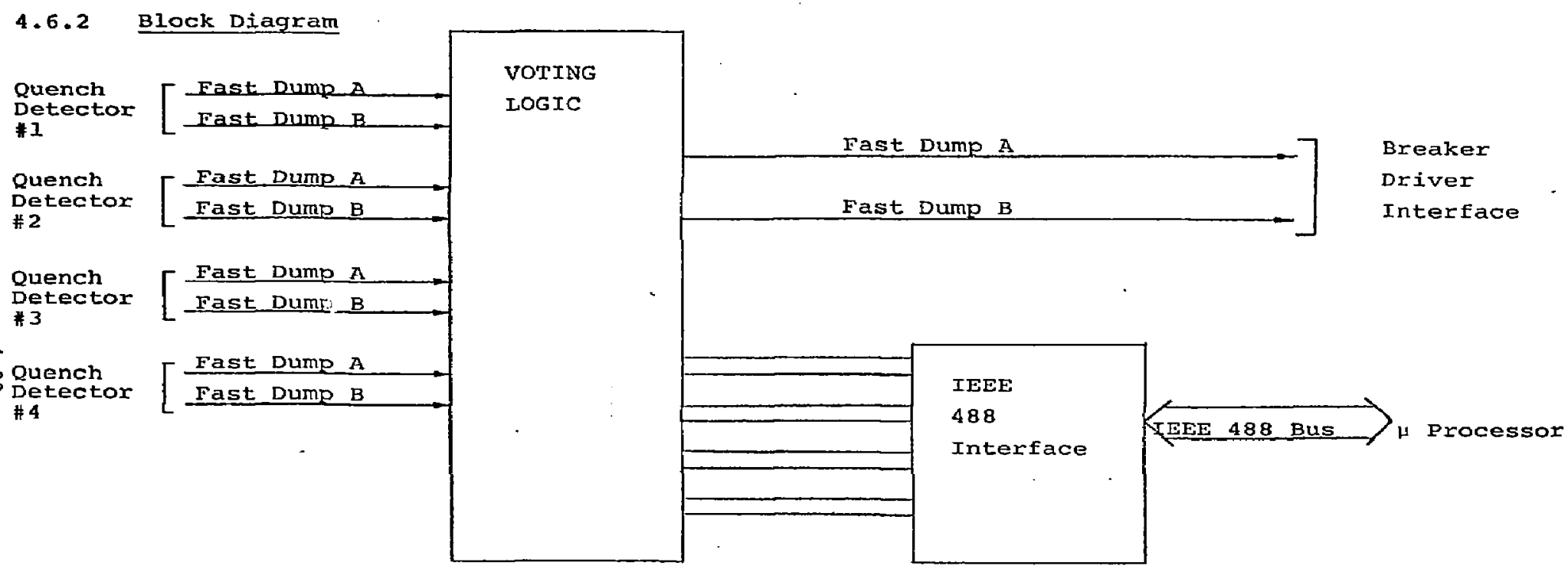

QUENCH DETECTOR VOTING LOGIC 


\subsection{Quench Detector Input Relay}

\subsubsection{Description :-}

The function of the quench detector input relay device is to prevent high magnet voltages from entering the quench detector inputs during a fast dump. Normally closed SPDT high voltage relays open the quench detector inputs including coaxial shields upon command. The relays are normally opened by the breaker driver interface when a fast dump has been initiated. The relays have a rated operating voltage of $8 \mathrm{kvdc}$. In addition, each output is protected by a zener diode-fuse combination in case the relay fails.

\section{Specifications \\ Inputs - (1) 24 vdc relay trip line \\ (5) voltage tap signal lines \\ Outputs - 5 separate output connectors. Each output comnector contains 3 voltage tap lines, connects up to 5 quench detectors in the configuration described in section 3.4 . \\ Power - 115 VAC, 1 A - Backup: 12 VDC, 5 A}




\subsection{IGC Current Controller Unit}

\subsubsection{Description}

The controller can be operated by an external computer or through front panei switches. Current level and current rate selection are set by thumbwhee1 switches on the front panel or by remote computer command. Magnet current and voltage are shown on front panel analog meters and are available to the magnet protection system as digital outputs via the IEEE 488 bus and the LIL computer through a separate interface bus. A front panel switch allows either magnet rate or power supply voltage to be monitored from a front panel analog meter. The setpoints for current and rate are shown on digital displays. Ramp-to-zero, rampto-level, and hold functions can be selected from front panel switches/indicator or by remote computer command through the LIL computer interface. Ramp-to-zero and ramp-to-level generate linear current ramp in the magnet at the selected rate. The hold function provides immediate unconditional ramp stop at the existing current. Two controllers can be operated independently or in tandem, where one controller acts as a master controlling both. Controllers are capable of either master or slave operation. The master control is selected from a master pushbutton on the front parel of a designated master unit or by remote computer command through the LLI computer inserface. When transitions are made from local, computer or master, the controller(s) are placed in hold to prevent possible undesirable magnet operation. Master, local and computer control functions can be selected from front panel switches/indicators or by remote computer command through the LLI computer interface. An at-level front panel indicator provides verification when the selected level is reached. An interlock input for the slow dump bus is provided so that in the case of an alarm all front panel switches and computer controls are overridden and the current controller is put in a ramp-tozero state until the alarm or slow dump bus is cleared. 
Also, if when in computer control the LLI computer fails to respona every second, the controller goes into an automatic rampdown to zero state.

Front panel pushbuttons are illuminated switches, which light up when depressed unless the controller is under computer control or unless it is locked up by the protection system. The pushbutton lights always indicate the state of the controlier.

\section{Specifications}

Inputs: $\quad$ Power Supply Analog Current Power Supply Analog Voltage Coil Analog Voltage

Slow Dump Bus

Analog Output: Analog current control signal $0-10 \mathrm{~V}$ \& $5 \mathrm{k} \Omega$

Digital Input/Output: I/O IEEE-488 Bus

ILI Computer I/O Indicator: slowdump

Power: $\quad 115 \mathrm{VAC}, 1 \mathrm{~A}$ - Backup: $12 \mathrm{VDC}, 5 \mathrm{~A}$ 
4.8.2 Eront panel

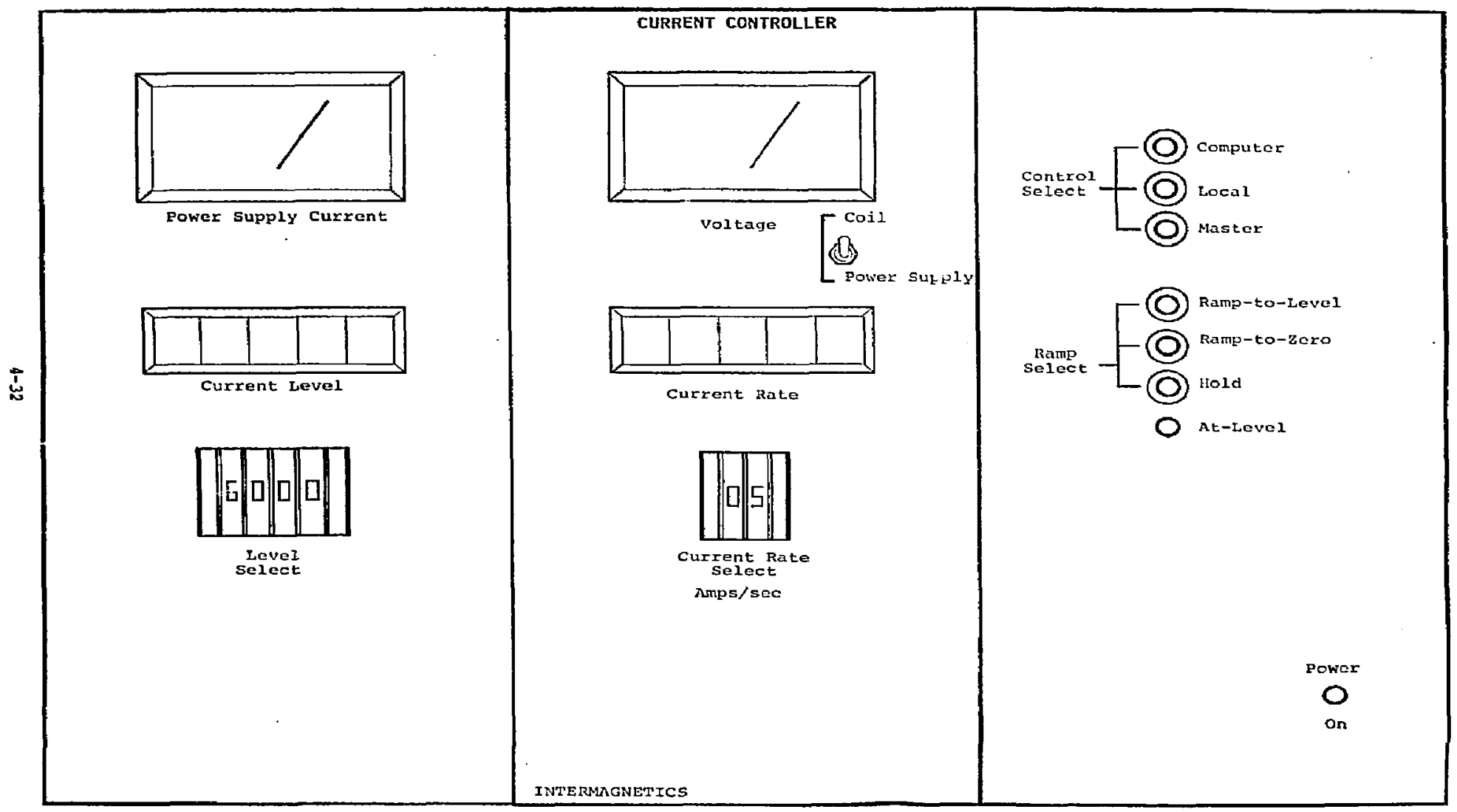




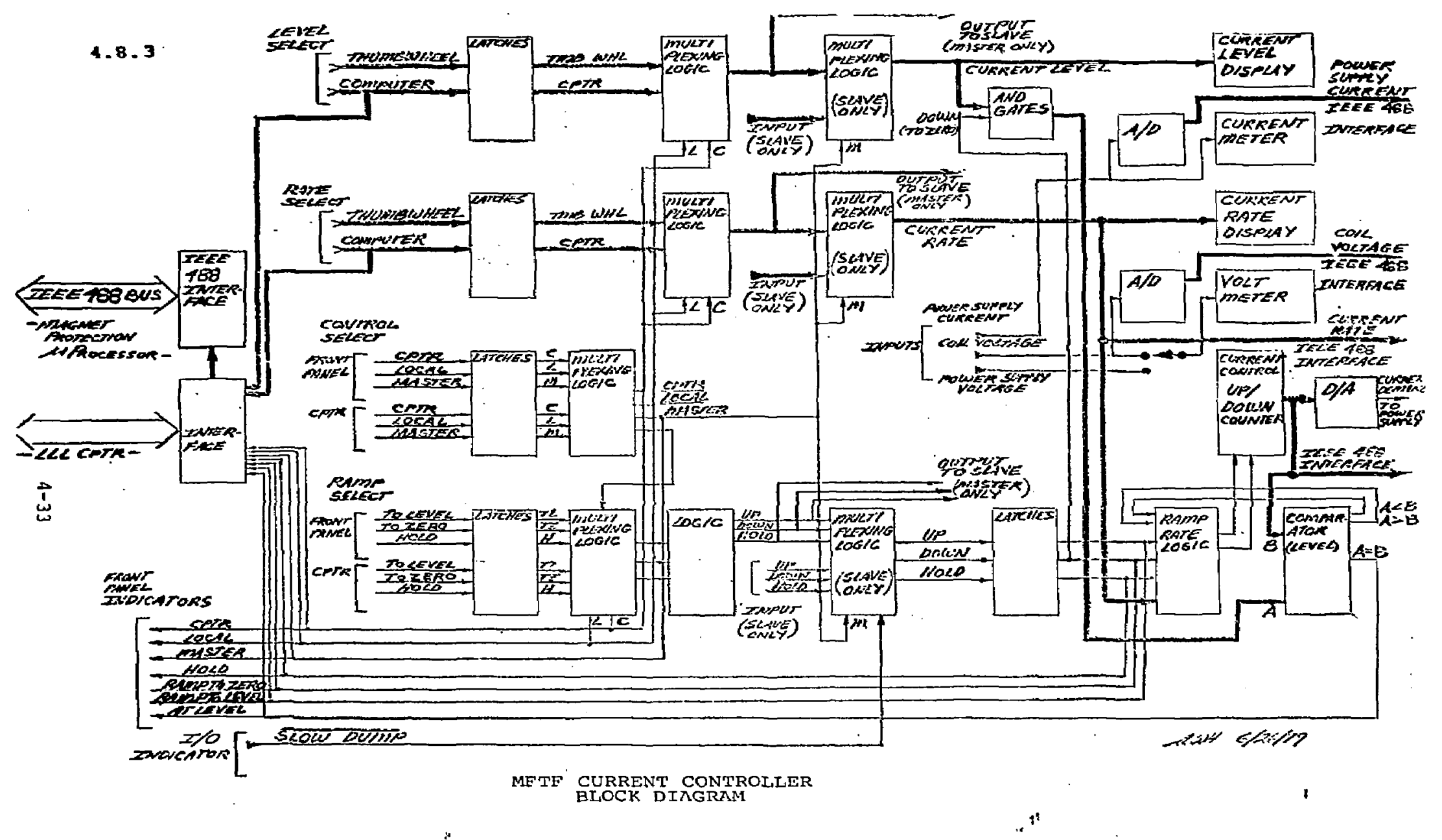




\subsection{Microprocessor Display}

\subsubsection{Description}

The display unit contains a gas discharge 32-character alphanumeric display and interface compatible with the IGC

microprocessor module.

\section{Specifications}

I/O Interface: IEEE-488 bus

$0.2^{\prime \prime} \times 0.14^{\prime \prime}$ character size

Display: $\quad 32$ alphanumeric $.2^{\prime \prime} \times .14^{\prime \prime}$ characters

Power: $\quad 115$ VAC, $1 \mathrm{~A}$ 
4.9 .2

Front Panel

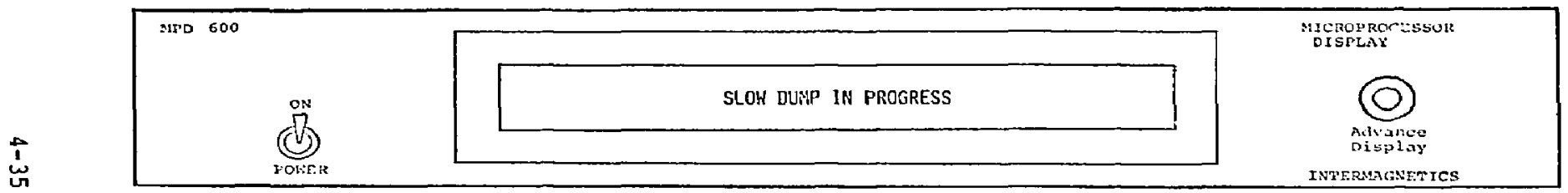

MICTOOPROCESSOR DISPIAY 
Although the recommended protection system appears extremely complicated, if one examines the main critical circuit paths, it is extremely simple. Only a few gates separate a given quench detector from the $6000 \mathrm{~A}$ fast dump breakers. The same situa"ion is true for the $s^{\circ}$ dump breaker. For example, the overpressure switch inputs fuss through only a few integrated circuits before activating the slow dump breaker. Much of the overhead in the system relates to the diagnostic capability, test capability and iditional reliability added to the system which will pay for itself in saved helium and downtime.

Superconducting magnets i.e somewhat unpredictable. Some have been known to quench after many hours of flawless operation. The danger is that personnel begin to believe that the magnet is safe and it does not need to be protected. When a small deviation from norm? operation occurs, a critical problem can go unnoticed, leaving the magnet open for damage. With a comrehensive protection system such as that recommended, this situation is unlike?y to happen.

Other approaches to the protection probleln have been considered. A package of any kind should be modular for accessibility and maintenance. Few commercial modular packages are designed for the rugged and noisy environment of a superconducting magnet, rather, most modilar packages are slanted ioward non-critical experimental process and control applications.

There are other needs such as redundancy, additional intermodule cabling, and self diagnostics that makes the MFTF protection magnet problem difficult to solve with mos:- standard test equipment and computer interface modules. 
Modification of equipment not specifically designed for the task nay precipitate a host of problems. H more reasonable approach is to uso specialized modules such as those described in this study to attack the problem.

Putting the entire protection system together will be a formidable problem. The software and systems integration effort is easy to underestimate. The hardware design and fabrication is more straightforward and can be done in a cost-effective fashion. But if the hariware is not properly integrated it can precipitate an fnormous system problem. In this study, we have carefully selected sach module to meet the needs of the system which should in the end *educe the magritude of the problem. 


\title{
6.0 REFERENCES
}

1. J. Powell, "Aspects of Safety and Reliability for Fusion Magret System", 1976, Brookhaven National Laboratory.

2. M. J. Hennessy and R. F. DiGesare, "A MicroprocessorBased Superconducting Magnet Protection System", 1978, IEEE irans. on Magnetics, Vol. MAG-15, Mo. 1, Jan. 1979, D. 860.

3. Donala Cornish, LLL, Private Communication.

4. Ibid

5. Ibid

6. J.b: d

7. Dan Shimer, LLL, Private Communication

8. Robert E. Schwall, ORNL, Private Communication

NOTICE

\begin{abstract}
"Work performed under the auspices of the L S. Depariment of Energy by the Lawfence Livermore Lahoratory under contract number $w$. 7405-ENG-48."

"This report was prepared as an account of work sponsored by the United Stales Government. Neilher the United Stutes nor the United States Department of Encrgy, nor any of their $\mathrm{em}$. ployes, nur any of their coniractors, subcontraclots, of their employecs, makkes any warranty, express or implied, or assurnes any icgal liability or icsponsibility for the accuracy, completeness of usclulness of any information, apparatus. product or process disclosed, or represents that its use would not infringe privately-owned rights."
\end{abstract}

Refcrence to a company o: product name does nol imply approval or recommendation of the pre by the University of California or the U. artment of Energy to the exclusion of others . may bu suilable. 